\title{
TITLE:
}

\section{Chemistry of porous coordination polymers}

$\operatorname{AUTHOR}(S)$ :

Maji, Tapas Kumar; Kitagawa, Susumu

CITATION:

Maji, Tapas Kumar ...[et al]. Chemistry of porous coordination polymers.

Pure and Applied Chemistry 2007, 79(12): 2155-2177

ISSUE DATE:

2007-12

URL:

http://hdl.handle.net/2433/84650

RIGHT:

Copyright (c) 2008 International Union of Pure and Applied Chemistry 


\title{
Chemistry of porous coordination polymers*
}

\author{
Tapas Kumar Maji ${ }^{1, \dagger}$ and Susumu Kitagawa ${ }^{2, \ddagger}$ \\ ${ }^{1}$ Chemistry and Physics of Materials Unit, Jawaharlal Nehru Centre for Advanced \\ Scientific Research, Jakkur, Bangalore, 560 064, India; ${ }^{2}$ Department of Synthetic \\ Chemistry and Biological Chemistry, Graduate School of Engineering, Kyoto \\ University, Katsura campus, Kyoto, 615-8510, Japan
}

\begin{abstract}
Remarkable advances in the recent development of porous compounds based upon coordination polymers have paved the way toward functional chemistry having potential applications such as gas storage, separation, and catalysis. From the synthetic point of view, the advantage is a designable framework, which can readily be constructed from building blocks, the so-called bottom-up assembly. Compared with conventional porous materials such as zeolites and activated carbons, porous inorganic-organic hybrid frameworks have higher potential for adsorption of small molecules because of their designability with respect to the coordination geometry around the central metal ion as well as size and probable multifunctionality of bridging organic ligands. Although rigidity and robustness of porous framework with different degree of adsorption are the most studied properties of metal-organic coordination frameworks, there are few studies on dynamic porous frameworks, which could open up a new dimension in materials chemistry.
\end{abstract}

Keywords: coordination polymers; porous networks; rigid frameworks; flexible frameworks; gas adsorption.

\section{INTRODUCTION}

Conventional microporous materials (zeolites and activated carbons), which have permanent porosity and high thermal stability conferred by the strong $\mathrm{Si}-\mathrm{O}$ or $\mathrm{C}-\mathrm{C}$ bonds, display various properties such as ion-exchange, adsorption (for separation), and catalysis [1-4]. Metal-organic porous coordination polymers based on the covalent bonds or weak noncovalent interactions cannot compete with the zeolites on the basis of thermal stability. Consequently, potential advantage could be sought, through unique functions conferred by the thermal and chemical stability of the oxide-based systems. Metal-organic porous coordination polymers have advantages with regard to the designibility, regularity, and versatility in correlation with architectural topology with controllable pore size (small to very large pores), using the potential utility of the various geometry of the metal ion (node) and size, shape, and multifunctionality of the organic bridging ligands (spacer) (Scheme 1) [5-15]. Over the past few years, a large number of studies have been made with the rigid and thermally stable porous frameworks, the so-called second-generation [6,8] compounds to carry out the porous functionalities, and in certain cases the adsorption properties surpass those of zeolites and activated carbons [16-26].

A recent development in this field is the flexible and dynamic porous frameworks, resulting from contrivances whereby flexible building units (or motifs) are linked via strong bonds, or stiff building

\footnotetext{
*Paper based on a presentation at the $9^{\text {th }}$ Eurasia Conference on Chemical Sciences, 9-13 September 2006, Antalya, Turkey. Other presentations are published in this issue, pp. 2101-2177.

$\dagger$ E-mail: tmaji@jncasr.ac.in

‡Corresponding author: E-mail: kitagawa@sbchem.kyoto-u.ac.jp
} 


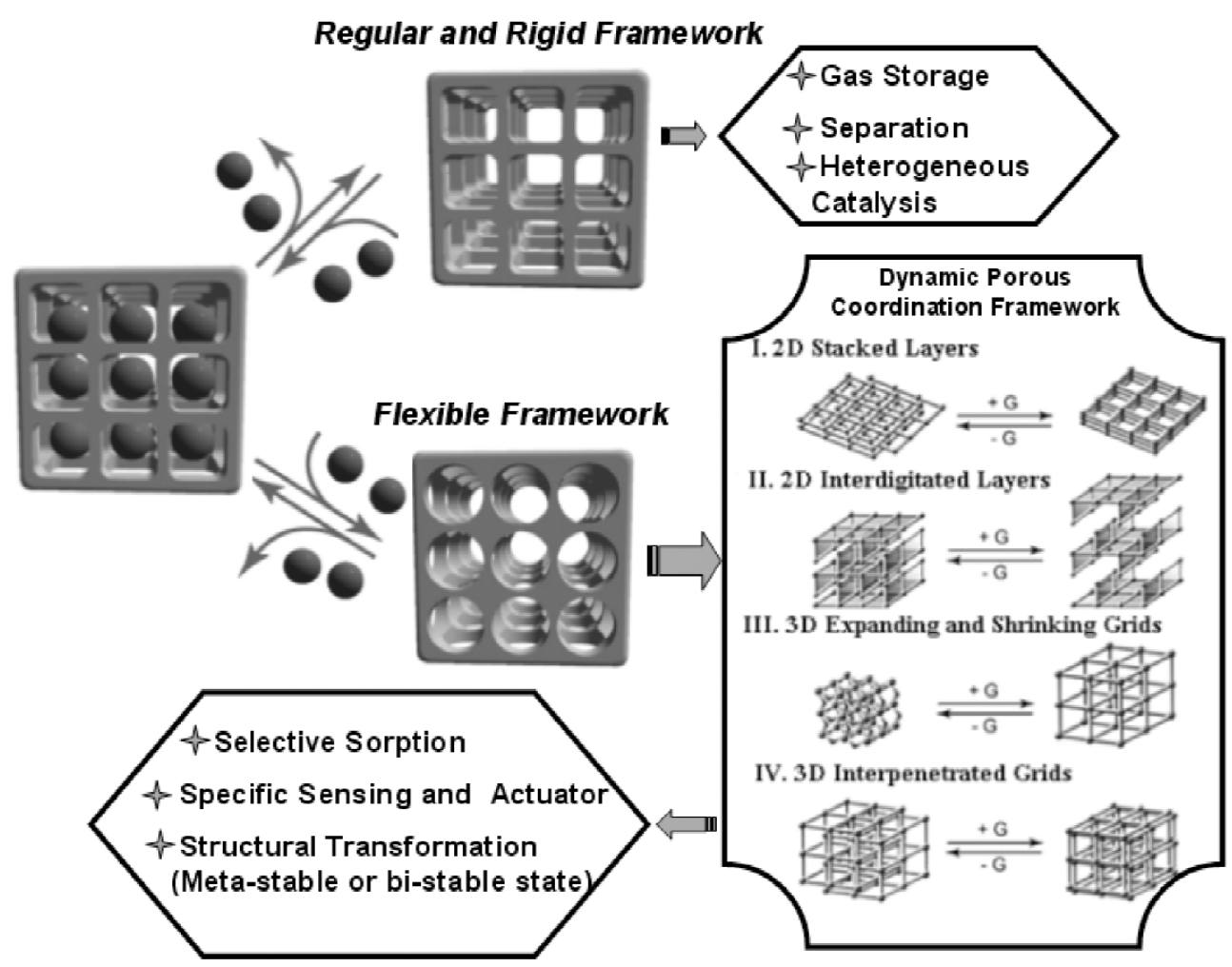

Scheme 1 Microporous coordination framework: Permanent porosity with multiple functionality.

blocks (or motifs) are connected via weak bonds (Scheme 1). Another possible option is the combination of flexible building blocks (motifs) and weak linkages [27-31]. This type of framework responds to the external stimulus, coming from a sort of "soft" framework with bistability, whose two states go back and forth between counterparts; a system could exist in one or two states for the same values of external parameters and be considered as a third-generation porous framework (Scheme 1) [32-59]. For weak linkages, guest molecules readily give rise to changes in orientation, distance, and cleavage of bonds, frameworks resulting in overall structural change because of a cooperative effect based on a large ensemble over an infinite entity [58]. Switchable properties accompanying framework change are characteristics of materials for signaling and sensing [35,36,52-54]. Flexibility and dynamicity of porous coordination materials thus offer control of pore shape/size and functionality derived from the components of $\pi$-electronic moieties, hydrogen-bonding, organic acid/base sites, or polar groups, leading to two fundamental structural transformation, shrinking, and expansion of the overall framework, which is exhibited by the unusual sorption and reaction properties, different from the rigid and stable frameworks $[32,39,44,52]$. The shrinking and expansion of the frameworks correlate well with guest shape sensitive fitting of the pore, in which a network is transformed to another form like bioenzymes, such as metalloproteins [60]. We can take advantage of their structural flexibility, which appears to be essential for their superb molecular recognition capability. Therefore, for porous coordination polymers, we also expect that host flexibility, the so-called "structural dynamism", would be a key principle for high selectivity recognition, accommodation, and separation of a target molecule, which constitutes a new class of practical materials. 


\section{POROUS METAL-ORGANIC COORDINATION POLYMERS: DESIGNABILITY, REGULARITY, AND RIGIDITY}

Porous coordination polymers have been explored as new kinds of materials that are expected to be more designable in pore size and shape, and the ability to store a desired compound is a typical property of porous materials. The adsorption of gases at ambient temperature is important for applications such as storage and transport. A rigid metal-organic coordination framework, $\left\{\left[\mathrm{Co}_{2}\left(4,4^{\prime} \text {-bipy }\right)_{3}\left(\mathrm{NO}_{3}\right)_{4}\right] \cdot 4 \mathrm{H}_{2} \mathrm{O}\right]_{n}$, is the first compound that shows the gas adsorption properties of $\mathrm{CH}_{4}, \mathrm{~N}_{2}$, and $\mathrm{O}_{2}$ at ambient temperature [61]. Another 3D rigid porous framework, $\left\{\left[\mathrm{Cu}\left(\mathrm{SiF}_{6}\right)\left(4,44^{\prime}-\right.\right.\right.$ bipy $\left.\left.)_{2}\right] \cdot 8 \mathrm{H}_{2} \mathrm{O}\right\}_{n}$, is also an important compound that can accommodate a large amount of $\mathrm{CH}_{4}$, greater than the zeolite $5 \mathrm{~A}$ at room temperature and relatively low pressure $\left(134 \mathrm{~cm}^{3}\right.$ (standard temperature and pressure, STP) $\mathrm{g}^{-1}$ at $298 \mathrm{~K}$ and $\left.36 \mathrm{~atm}\right)$ [16].

Yaghi et al. have designed and synthesized a number of porous solids (metal-organic frameworks, MOFs) with controlled pore size and chemical functionality. For example, reactions of the rigid linear linkers, 1,4-benzenedicarboxylate (BDC) groups with $\mathrm{Zn}$ (II) ions led to a series of isoreticular 3D porous MOFs of general formula $\mathrm{Zn}_{4} \mathrm{O}$ (R-BDC), denoted as IRMOF. Sixteen such frameworks were prepared, and all of them show the same network topology [17]. The framework consists of oxo-centered $\mathrm{Zn}_{4} \mathrm{O}$ tetrahedron located at the edges of the cube and bridged by six carboxylate units to give secondary building units (SBUs) (Fig. 1a). These SBUs are further connected by the bridging dicarboxylate, resulting in the 3D cubic networks (Fig. 1a). The pore size can be controlled by using biphenyl, tetrahydropyrene, pyrene, and terphenyl carboxylate linkers with additional incorporation of various functional groups, such as $-\mathrm{Br},-\mathrm{NH}_{2},-\mathrm{OC}_{3} \mathrm{H}_{7}, \mathrm{OC}_{5} \mathrm{H}_{11},-\mathrm{C}_{2} \mathrm{H}_{4}$, and $-\mathrm{C}_{4} \mathrm{H}_{4}$, which are oriented toward the pore (Fig. 1b). The resulting networks are highly porous with very low densities and the void space for these networks, ranging from 55.8 to $91.1 \%$ of the total crystal volume, and the density is in the range of 1 to $0.21 \mathrm{~g} / \mathrm{cm}^{3}$. These materials have shown the utility in gas storage, e.g., IRMOF- 6 has a very high surface area of $2630 \mathrm{~m}^{2} / \mathrm{g}$ and its methane storage capacity is about $240 \mathrm{~cm}^{3} \mathrm{~g}^{-1}$ at STP (Fig. 1c). Other types of frameworks, called a jungle-gym form, were reported by K. Seki [24,42], one of which has a high $\mathrm{CH}_{4}$ sorption property.

Our group has designed and systematically synthesized coordination pillared-layer structures (CPLs) in different metal systems such as $\mathrm{Cu}(\mathrm{II})$ and $\mathrm{Cd}(\mathrm{II})$, exhibiting the controlled porous functionalities in a rationalized way $[32,62]$. With a very simple approach, first a $2 \mathrm{D}$ neutral layer structure was made with a simple dicarboxylate, pyrazine-2,3-dicarboxylate (pzdc), and each layer was connected by the different organic pillars, such as pyrazine, 4,4'-bipyridine (bipy) to make 3D microporous coordination frameworks (Fig. 2a). This kind of framework has many advantages such as: (a) the dimensions and characteristics of channel structures of these networks are apparently controllable by changing the lengths of organic pillars; (b) generally, interpenetration does not occur because the metal-metal separation in the layer is not so large; (c) high thermal stability; and (d) the introduction of the functional groups in the pillar module can provide different kinds of porous functionalities. The smallest member of this series is $\left\{\left[\mathrm{Cu}(\mathrm{pzdc})_{2}(\text { pyz })\right]\left(2 \mathrm{H}_{2} \mathrm{O}\right)\right\}_{n}$ (CPL-1), which has a $2 \mathrm{D}$ sheet of $\{\mathrm{Cu}(\mathrm{pzdc})\}_{n}$ and is connected by a small pyrazine pillar forming a 3D network with a water-filled channel $(4 \times 6 \AA)$ along the $c$-axis [62]. This compound is very effective for the accommodation of small molecules, such as $\mathrm{CH}_{4}, \mathrm{O}_{2}, \mathrm{~N}_{2}, \mathrm{CO}_{2}$, etc., which were characterized by the structure determination. $\mathrm{O}_{2}$ was dosed in CPL-1, and in situ synchrotron X-ray diffraction (XRD) pattern was measured at $80 \mathrm{kPa}$ over the temperature range 300-90 K [63]. The structure was determined by MEM/Rietveld analysis, showing that two $\mathrm{O}_{2}$ molecules adsorbed in the nanochannels formed van der Waals dimers, $\left(\mathrm{O}_{2}\right)_{2}$ and each dimer aligns along the $a$-axis in a closely packed way to form a $1 \mathrm{D}$ ladder-like structure (Fig. 2b). The magnetic susceptibility of adsorbed $\mathrm{O}_{2}$ molecules indicates nonmagnetic ground state associated with the antiferromagnetic dimer, and the interaction is twice as large as that in a bulk $\alpha$-phase. In other results, the sorption isotherms of $\mathrm{C}_{2} \mathrm{H}_{2}$ and $\mathrm{CO}_{2}$ at 270,300 , and $310 \mathrm{~K}$ were measured on the anhydrous sample of CPL-1, which shows a steep rise in the case of $\mathrm{C}_{2} \mathrm{H}_{2}$ at very low pressure region 
(a)

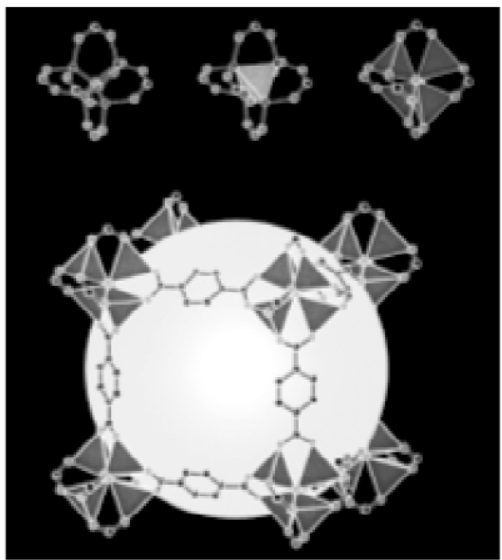

(c)
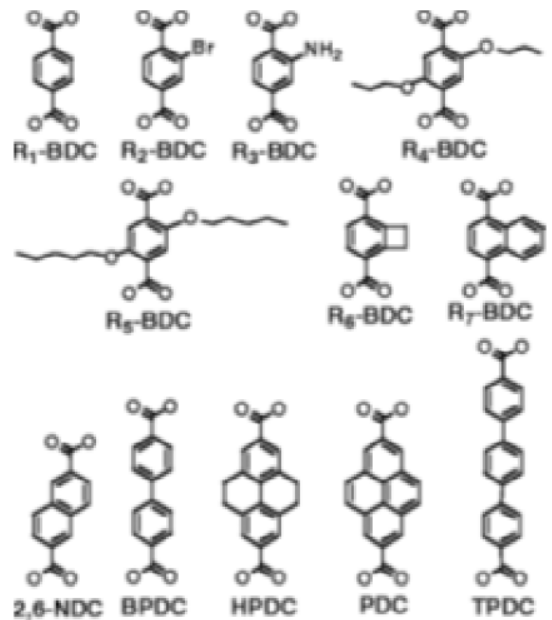

(b)

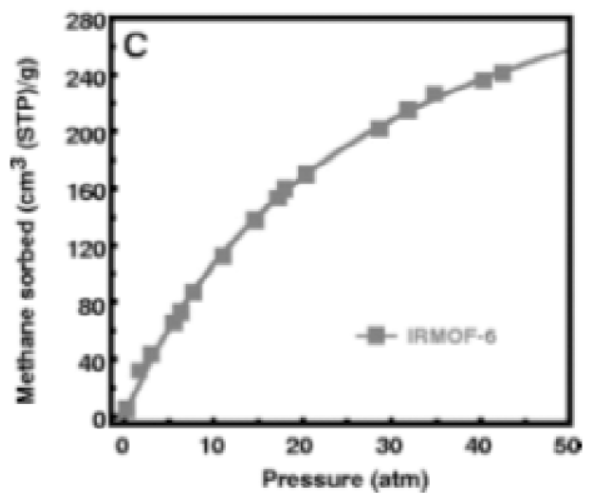

Fig. 1 (a) Structure of IRMOF-1 illustrated for a single cube fragment of their perspective cube 3D extended structure. On each of the corners is a cluster $\left[\mathrm{O}-\mathrm{Zn}_{4}\left(\mathrm{CO}_{2}\right)_{6}\right]$ of an oxygen-centered $\mathrm{Zn}_{4}$ tetrahedron that is bridged by six carboxylates of an organic linker; (b) Schematic diagram of the dicarboxylate with different size and functional groups; (c) Volumetric uptake of methane gas filled at $298 \mathrm{~K}$ in IRMOF-6.

and reaches saturation, whereas those of $\mathrm{CO}_{2}$ indicate gradual adsorption [64]. Like as for $\mathrm{O}_{2}$, the crystal structure and electron density of CPL-1 with $\mathrm{C}_{2} \mathrm{H}_{2}$ at $10 \mathrm{kPa}$ and $170 \mathrm{~K}$ were determined by the MEM/Rietveld analysis. Only one $\mathrm{C}_{2} \mathrm{H}_{2}$ molecule was located on the middle of the channel with strong $\mathrm{C}-\mathrm{H} \cdots \mathrm{O}(2.2 \AA)$ hydrogen-bonding interaction with the channel oxygen (Fig. $2 \mathrm{c}$ ), unlike the dimer of $\mathrm{O}_{2}$, and they are densely packed with $4.8 \AA$ intermolecular distances along the $a$-axis. This result shows the stable storage of $\mathrm{C}_{2} \mathrm{H}_{2}$ at a density 200 times larger than in the case of safe compression limit of free acetylene at room temperature. 


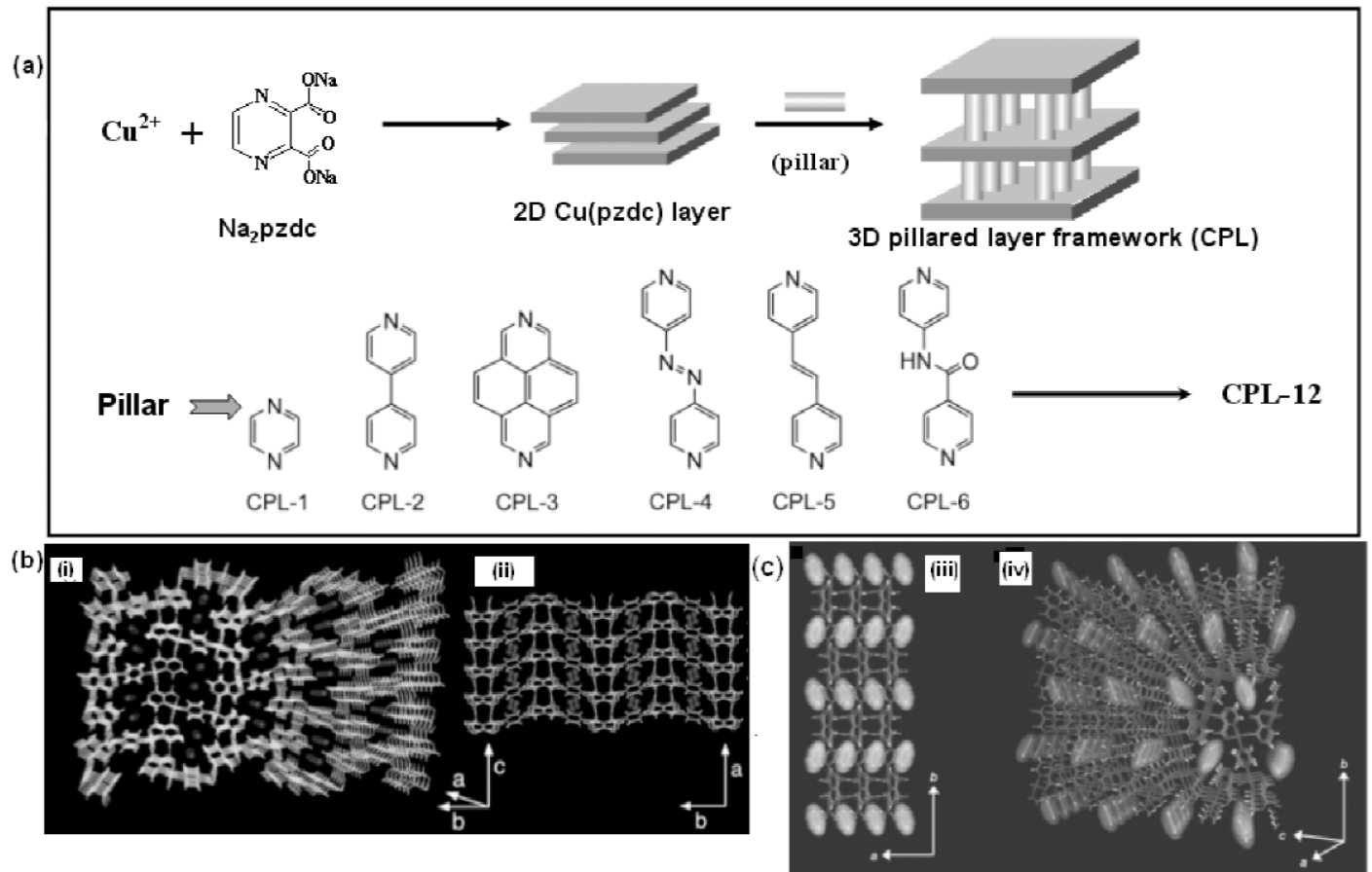

Fig. 2 (a) Schematic diagram of the design and synthesis of pillared-layer coordination framework (CPL) with different pillar motifs; (b) CPL-1 with the alignment of the van der Waals dimer of oxygen, $\left(\mathrm{O}_{2}\right)_{2}$, exhibiting the ladder-like structure in the nanochannel; (c) $1 \mathrm{D}$ alignment of acetylene $\left(\mathrm{C}_{2} \mathrm{H}_{2}\right)$ molecules with $\mathrm{H}$-bonding interaction in the pore surface with pendent O-atom of the pzdc in CPL-1.

\section{GENERATION OF FLEXIBLE FRAMEWORKS: AN OUTLINE}

A key for creating flexible and dynamic frameworks is to utilize weak molecular interactions in addition to the strong covalent and coordination bonds. Actually, coordination bonds in coordination frameworks are frequently sustained by hydrogen bonds, $\pi-\pi$ interactions, and other weak interactive forces. These intermolecular weak forces produce flexible parts in the porous network so that the system can exist in two or more solid forms, depending on the external perturbations. Interestingly, even for 3D coordination architectures, a sort of flexibility could be generated because a coordination framework is an assembled form of versatile geometry metal ion connector and flexible organic ligand linkers. As in the case of the $\mathrm{Cu}$ (II) framework, a flexible coordination geometry is observed at the apical position exhibited by the Jahn-Teller distortion. In the case of some organic linkers, there is flexibility of a free rotation around the $\mathrm{C}-\mathrm{C}$ bond of bipyridyl or an $\mathrm{sp}^{3}$-hybridized ethylene moiety.

The third-generation compounds [6,8] have bistable states and can alter their frameworks in response to the external stimuli. Third-generation compounds show characteristic sorption behavior (such as high selectivity for adsorption, hysteretic sorption behavior, and stepwise adsorption), and framework flexibility is a prerequisite for such porous functionality. Therefore, we can expect that this kind of porous coordination framework will find real applications for gas separation, sensing, and actuating. Because dynamic porous networks exhibit novel functions, it is important to look for the guidelines for their rational design and synthesis. One of the most promising techniques is to design a building block which could produce flexible and dynamic porous function when it is introduced in the framework. 
Flexible frameworks show various structural transformations, and in just a few years, different guest-induced structural modifications have been observed which can be simplified in the following ways:

- Guest-induced crystal-to-amorphous transformation: The framework collapses when the templated solvent molecules are removed from the channels. This occurs because of the close packing force between the guest and host molecules; however, it regenerates under the initial conditions.

- Guest-induced crystal-to-crystal transformation: In the porous network, when the guest molecule is removed or exchange with some other solvents, some structural changes result with retention of crystallinity.

Guest-induced structural transformation is ascribed to the stretching motions, rotations, and breathing in the porous framework, which are sometimes concomitant with the bond formation and bond cleavage. The key factors of realizing this kind of structural transformation is the utilization of the weak interactions, such as hydrogen bonds, semi-coordination bonds, $\pi-\pi$ interactions, and elongated coordination of Jahn-Teller distortions. The structural properties and functions of coordination networks therefore range from the robust to the flexible and dynamic.

\section{GUEST-INDUCED FIT: SHRINKING AND EXPANSION OF POROUS MODULATION}

In the case of flexible porous frameworks, two kinds of fundamental pore deformation (i.e., shrinking and expansion) occur, which are prerequisite for the effective accommodation of particular guest molecules. Upon the inclusion of guest molecules, shrinkage of a framework gives rise to the change of pore size and shape that is well suited to that of the guest molecules, and, therefore, short-range attractive interactions work effectively. To date, several shrinkable and expandable porous modules have been reported, which are well characterized by X-ray crystallographic structure determination.

A porous coordination polymer with a pillared-layer structure $(\mathbf{C P L})\left\{\left[\mathrm{Cu}(\mathrm{pzdc})_{2}\left(4,4^{\prime}-\right.\right.\right.$ bipy $\left.)]\left(6 \mathrm{H}_{2} \mathrm{O}\right)\right\}_{n}(\mathbf{C P L}-2)($ pzdc $=$ pyrazine-2,3-dicarboxylate, bipy = 4,4'-bipyridine $)$ was constructed from stiff motif, bipy and pyrazine ring of the pzdc, a flexible motif of the carboxyl group with rotational freedom, and a copper ion geometry that possesses a degree of flexibility in bond cleavage [52]. The permanent porosity $\left(8 \times 6 \AA^{2}\right)$ of the host framework demonstrated by $\mathrm{N}_{2}$ sorption at $77 \mathrm{~K}$ with type-I behavior. The most interesting phenomenon was observed in the case of benzene sorption, which can accommodate one benzene molecule in each pore with breaking one of the $\mathrm{Cu}-\mathrm{O}(\mathrm{pzdc})$ bonds in such a way that the framework is significantly contracted to perfect fitting of the benzene molecule (Fig. 3a). Because of the anisotropic (nonspherical) shape, benzene molecules cannot be accommodated effectively in the rectangular micropore, and, consequently, "shape-responsive fitting"-type crystal-tocrystal transformation occurs with a large cell contraction (Fig. 3b). The additional interaction energy may compensate for the energy loss from bond cleavage of the $\mathrm{Cu}-\mathrm{O}$ bond moiety (Fig. 3c). The host flexibility improves the efficiency of the adsorption by aiding the host structural transformation suited for incorporating the guest molecules. 
(a)

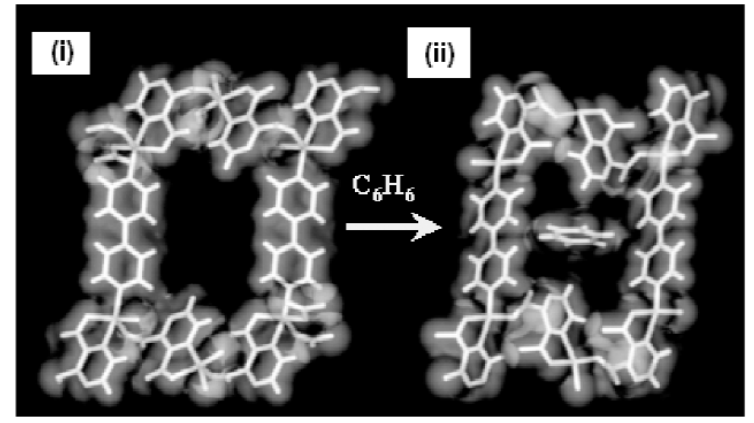

(c)

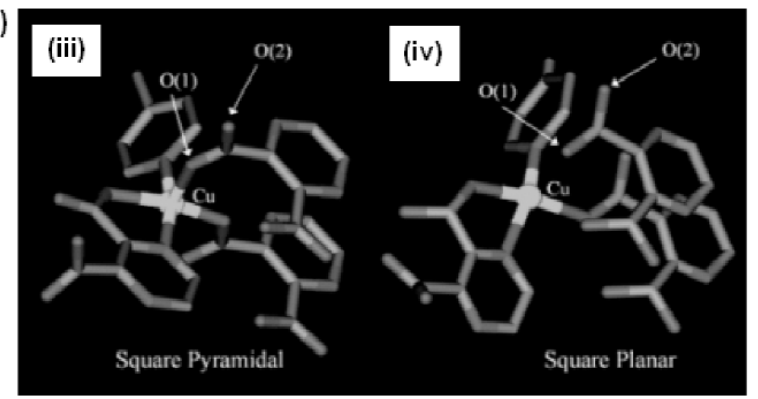

(b)

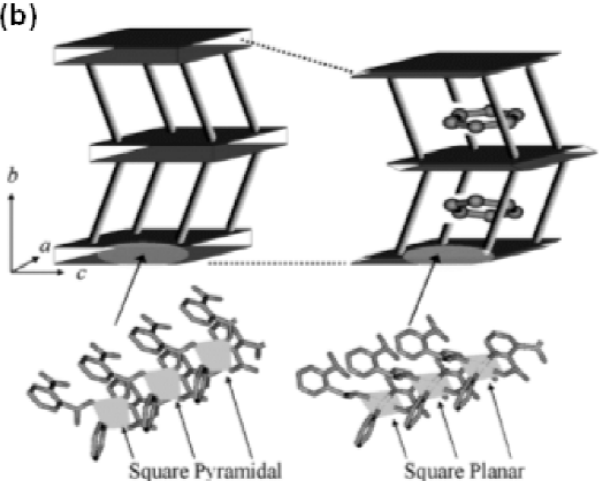

Fig. 3 (a) Representation of the pore structures of (i) $\left[\mathrm{Cu}_{2}(\mathrm{pzdc})_{2}(\mathrm{bpy})\right]$ (CPL-2) and (ii) CPL-2-benzene. Both views are down from the $a$-axis; (b) The geometry around the $\mathrm{Cu}$ atom; (iii) CPL-2 indicates a square pyramidal form and (iv) CPL-2.benzene indicates a square planar form; (c) Schematic representation of the structural transformation with "Shape-responsive fitting" triggered by benzene adsorption. The mutual slide of the 2D sheets and the pore shrinking are observed, which are accompanied by the change of the $\mathrm{Cu}$ coordination geometry from a square pyramid to a square plane.

In the framework, $\left[\mathrm{Zn}_{2}(1,4-\mathrm{bdc})_{2}(\mathrm{dabco})\right] \cdot 4 \mathrm{DMF} \cdot 1 / 2 \mathrm{H}_{2} \mathrm{O}$, dinuclear $\mathrm{Zn}_{2}$ units are bridged by 1,4-bdc to form a distorted $2 \mathrm{D}$ square grid $\left\{\mathrm{Zn}_{2}(1,4-\mathrm{bdc})\right\}$, which is further pillared by dabco ligand to form a $\alpha$-Po type (jungle gym-like) 3D network (Fig. 4a) [53]. Interestingly, the linear and rigid linker, 1,4-bdc is unusually bent in the framework causing a twist from an ideal square grid network (Fig. 4b). The structure determination of the desolvated framework reveals that a perfect $2 \mathrm{D}$ square grid with straight 1,4-bdc ligands linking the $\mathrm{Zn}_{2}$ paddle-wheels and the cell volume increases from 1091.8(4) $\AA^{3}$ to $1147.6(3) \AA^{3}$ with subsequent increase in the effective pore size (Fig. 4b). The permanent porosity of the guest free framework is confirmed by $\mathrm{N}_{2}$ sorption (surface area $1450 \mathrm{~m}^{2} \mathrm{~g}^{-1}$ ), and $\mathrm{H}_{2}$ sorption showing a maximum sorption capacity of $225 \mathrm{~cm}^{3} \mathrm{~g}^{-1}$ (STP) or $2.0 \mathrm{wt} \%$ at 1 bar pressure (Fig. 4c). Shrinkage of the pores was observed upon inclusion of benzene into the guest free framework as confirmed by the powder X-ray diffraction (PXRD) and single-crystal structure determination (Fig. 4d). Structure of the benzene inclusion framework, $\left[\mathrm{Zn}_{2}(1,4-\mathrm{bdc})_{2}(\right.$ dabco $\left.)\right] \cdot 2 \mathrm{C}_{6} \mathrm{H}_{6}$ shows that $\mathrm{Zn}_{2}$ paddlewheels and 1,4-bdc linkers form a 2D rhombic grid (Fig. 4c), and due to the inclination of the 2D grid motifs, the specific volume has decreased to 1114.2(2) $\AA^{3}$. So these results show that the porous MOF responds to the guest inclusion in different ways depending on the nature of the guest. 


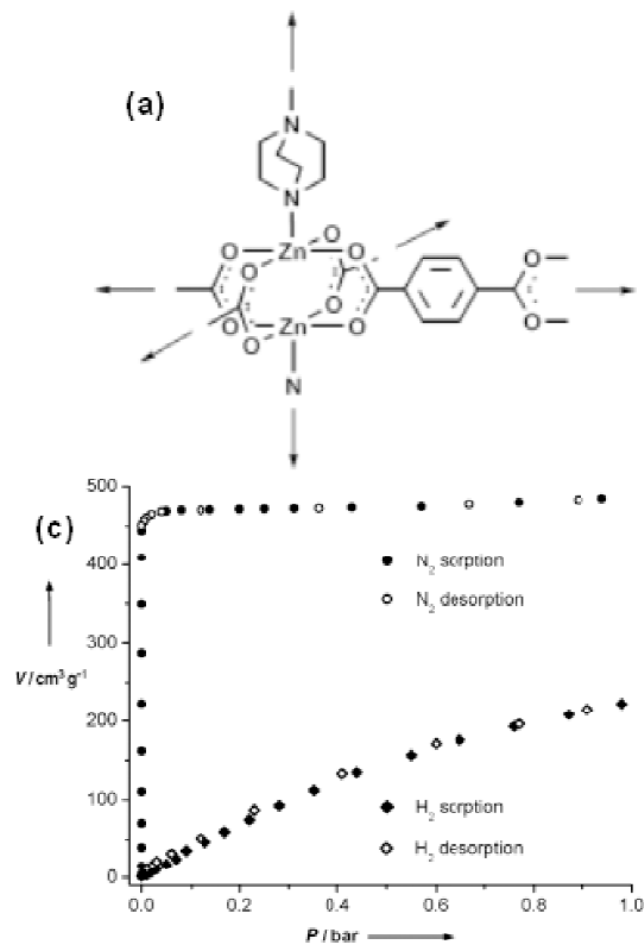

(b)

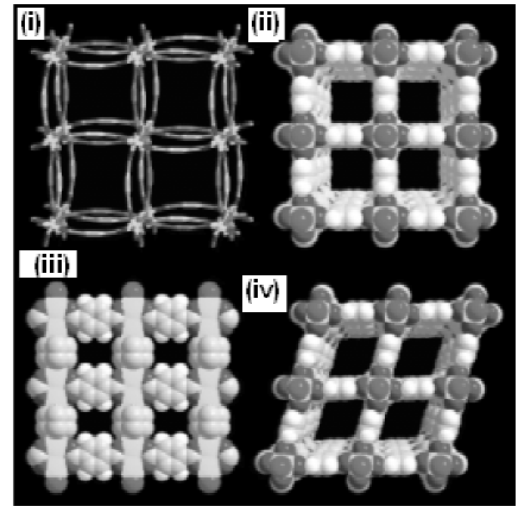

(d)

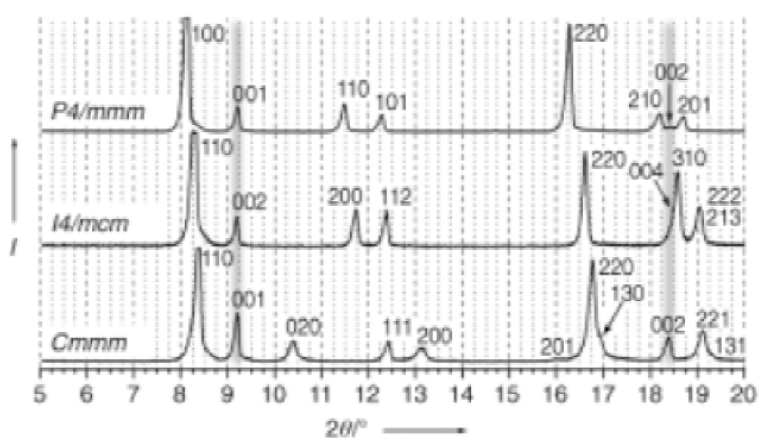

Fig. 4 (a) Schematic diagram of the extension of the 2D square-grid of $\left\{\mathrm{Zn}_{2}(1,4-\mathrm{bdc})_{2}\right\}$ into a 3D structure by using dabco, which occupies the axial positions; (b) (i) The view along fourfold axis of the MOF structure in $\left[\mathrm{Zn}_{2}(1,4-\right.$ bdc $\left.)_{2}(\mathrm{dabco})\right] \cdot 4 \mathrm{DMF} \cdot 1 / 2 \mathrm{H}_{2} \mathrm{O}$. One $\left\{\mathrm{Zn}_{2}(1,4-\mathrm{bdc})_{2}\right\} 2 \mathrm{D}$ layer is colored orange to emphasize the alternation of stacking layer, (ii) Space-filling representation of evacuated framework, which emphasizes the open square channels; view along fourfold axis, (iii) Side view of evacuated framework $\left[\mathrm{Zn}_{2}(1,4-\mathrm{bdc})_{2}(\mathrm{dabco})\right]$, showing the windows interconnecting the channels, (iv) Space-filling representation of $\left[\mathrm{Zn}_{2}(1,4-\mathrm{bdc})_{2}(\mathrm{dabco})\right]$ in $\mathrm{C}_{6} \mathrm{H}_{6}$, showing rhombic-grid motif of $\left\{\mathrm{Zn}_{2}(1,4-\text { bdc })_{2}\right\}$ layers; (c) $\mathrm{N}_{2}$ and $\mathrm{H}_{2}$ sorption profile in $\left[\mathrm{Zn}_{2}(1,4-\mathrm{bdc})_{2}(\mathrm{dabco})\right]$ at $78 \mathrm{~K}$; (d) PXRDs of evacuated (top), as-synthesized (middle), and benzene-exchanged (bottom) frameworks.

Modification in the functionality of the pillar module controls the sorption, and a typical example was recently reported in 3D pillared-layer framework of $\mathrm{Cd}(\mathrm{II}),\left\{[\mathrm{Cd}(\mathrm{pzdc})(\mathrm{azpy})] 2 \mathrm{H}_{2} \mathrm{O}\right\}_{n}$ and $\left\{\left[\mathrm{Cd}(\text { pzdc) }(\text { bpee })] 1.5 \mathrm{H}_{2} \mathrm{O}\right\}_{n}\right.$ (azpy = 4,4'-azopyridine; bpee = 1,2-bis(4-pyridyl)ethylene) [32]. The crystal structures show that the $2 \mathrm{D}$ corrugated sheet of $\{\mathrm{Cd}(\mathrm{pzdc})\}_{n}$ are pillared axially by azpy or bpee ligand forming two isostructural 3D networks (Fig. 5a). The most interesting aspect of the structure is that the pillar azpy or bpee are canted and in a criss-cross manner to facilitate the $\pi-\pi$ interaction, resulting in $\alpha$-Po-type 3D networks with 1D water-filled channel along the crystallographic $c$-axis. The framework $\left\{[\mathrm{Cd}(\text { pzdc })(\text { azpy })] 2 \mathrm{H}_{2} \mathrm{O}\right\}_{n}\left(V_{\text {void }}=20.3 \%\right.$, pore size $\left.=3.5 \times 6.1 \AA^{2}\right)$ is stable up to $265^{\circ} \mathrm{C}$, and the PXRD patterns show that the (200) peak shifted to a lower angle upon dehydration, indicating the expansion along the $a$-axis. On the other hand, $\left\{[\mathrm{Cd}(\mathrm{pzdc})(\mathrm{bpee})] 1.5 \mathrm{H}_{2} \mathrm{O}\right\}_{n}\left(V_{\text {void }}=19.3 \%\right.$, pore size $=3.5 \times 4.5 \AA^{2}, T_{\text {decom. }}=260{ }^{\circ} \mathrm{C}$ ) upon dehydration the (200) peak shifted to a higher angle, indicating that the shrinking occurs along the $a$-axis. The structure determination of the dehydrated framework of $\left\{[\mathrm{Cd}(\mathrm{pzdc})(\text { azpy })] 2 \mathrm{H}_{2} \mathrm{O}\right\}_{n}$ indicates that there is a significant increase in cell volume along with pore size $\left(3.7 \times 6.4 \AA^{2}\right)$ and void space $\left(V_{\text {void }}=21.2 \%\right)$. This expansion is attributed to the lone pair-lone pair electronic repulsion from the pendent oxygen atom of the carboxylate and nitrogen atom of the azo-group of azpy (Fig. 5b). In contrast, the interlayer distance of $\{\mathrm{Cd}(\mathrm{pzdc})(\mathrm{bpee})\}_{n}$ decreases because the pendent oxygen atom is in close contact with the ethylene hydrogen atom of the bpee pil- 
(a)

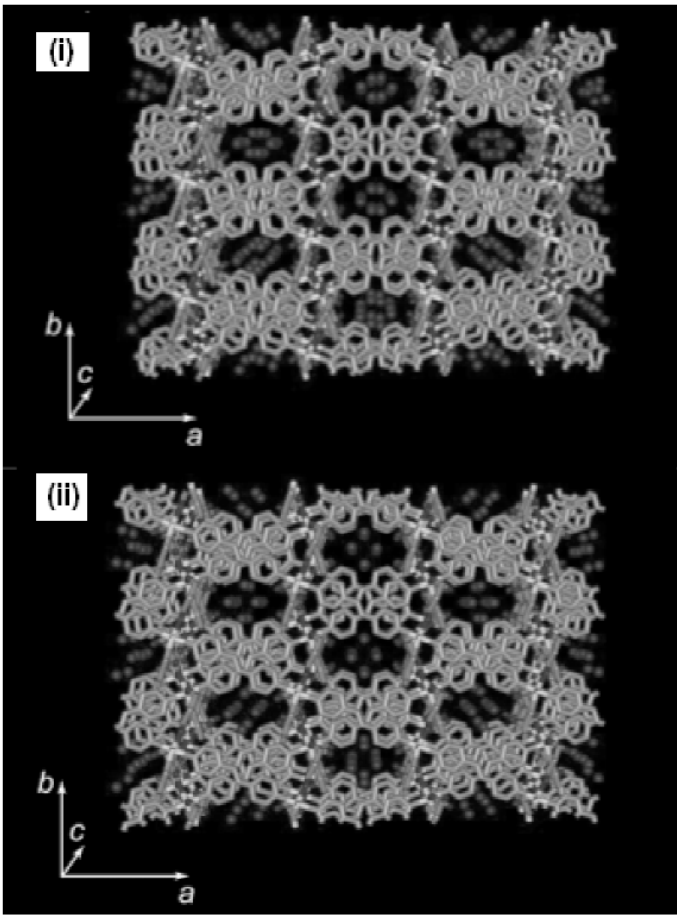

(b)
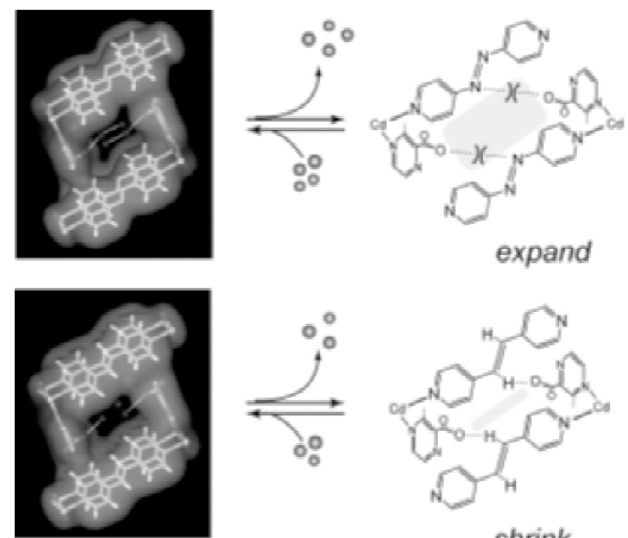

$\mathrm{O}=\mathrm{H}_{2} \mathrm{O}$

shrink

Fig. 5 (a) View of the criss-cross and canted pillared-layer structures of (i) $\left\{[\mathrm{Cd}(\mathrm{pzdc})(\operatorname{azpy})] \cdot 2 \mathrm{H}_{2} \mathrm{O}\right\}_{n}$, and (ii) $\left\{[\mathrm{Cd}(\mathrm{pzdc})(\mathrm{bpee})] \cdot 1.5 \mathrm{H}_{2} \mathrm{O}\right\}_{n}$, along the $c$-axis; (b) Views of the pores and schematic diagram of the mechanism of the expansion and shrinking in the frameworks.

lar, giving rise to $\mathrm{O} \cdots \mathrm{HC}=\mathrm{CH}$ hydrogen-bonding interaction and, therefore, forming closely packed structure with shrinkage (Fig. 5b). The dehydrated compound of both the frameworks was subjected to the sorption properties with the number of adsorbates and indicates no sorption for $\mathrm{N}_{2}$ (at $77 \mathrm{~K}$ ) in both cases. $\mathrm{H}_{2} \mathrm{O}, \mathrm{MeOH}, \mathrm{EtOH}, \mathrm{THF}$, and $\mathrm{Me}_{2} \mathrm{CO}$ molecules can diffuse into the micropore of $\{\mathrm{Cd}(\mathrm{pzdc})(\text { azpy })\}_{n}$, and, on the other hand, the $\{\mathrm{Cd}(\mathrm{pzdc})(\text { bpee })\}_{n}$ can accommodate $\mathrm{H}_{2} \mathrm{O}$ and $\mathrm{MeOH}$ but not EtOH, THF, and $\mathrm{Me}_{2} \mathrm{CO}$ molecules in the pore, exhibiting selectivity in sorption properties. Just changing the functionality of the pillar module, unprecedented expansion and shrinking phenomenon are induced and selective sorption phenomenon can be realized.

Synthesis of coordination polymers based on trivalent ions has not been well explored but shows considerable promise. Three-dimensional $\left\{[\mathrm{Cr}(\mathrm{OH})(1,4-\mathrm{bdc})] \cdot 11 \mathrm{H}_{2} \mathrm{O}\right\}$ have been prepared solvothermally in aqueous phase and show that each $\mathrm{Cr}$ (III) octahedra are bridged by 1,4-bdc and $\mathrm{OH}$ ions and result in 1D channels filled with water molecules [44]. The transition between the hydrated form and anhydrous solid is fully reversible and followed by a very high breathing effect, the pores being shrunken in the presence of water and expanded when the channels are empty. The selective uptake of the guest, DMF in compare to the $\mathrm{Me}_{2} \mathrm{CO}$ and $\mathrm{EtOH}$, is correlated with the strong $\mathrm{H}$-bonds of the hydroxyl groups of the framework. The Neel temperature of $65 \mathrm{~K}$ is notable, as is the transition to canted antiferromagnetism once guests are incorporated. The dehydrated compound $[\mathrm{Cr}(\mathrm{OH})(1,4$-bdc $)]$ was subjected to the sorption properties with $\mathrm{CH}_{4}$ and $\mathrm{CO}_{2}$ at $304 \mathrm{~K}$ and up to pressure of 30 bar [65]. The most interesting stepwise adsorption phenomenon was observed in the case of $\mathrm{CO}_{2}$ but not with $\mathrm{CH}_{4}$. This is attributed to the fact that $\mathrm{CO}_{2}$ has a significant permanent quadruple moment, which induces specific interactions with adsorbents, whereas $\mathrm{CH}_{4}$ has not. The specific interactions with $\mathrm{CO}_{2}$ and 
values ( $<6$ bar). The further increase in the adsorption pressure leads to a reopening of the total porosity and total pore filling.

\section{FLEXIBILITY: DYNAMIC BEHAVIOR, GUEST-RESPONSIVE FRAMEWORKS, AND CRYSTAL-TO-CRYSTAL TRANSFORMATION TRIGGERED BY GUEST EXCHANGE}

Structural transformation by guest exchange in the form of anion-exchange was reported in 1996. The addition of a slight excess of $\mathrm{NaPF}_{6}$ to a suspension of crystalline $\left[\mathrm{Ag}\left(\mathrm{NO}_{3}\right)\left(4,4^{\prime} \text {-bipy }\right)\right]_{n}$ in water at room temperature causes the exchange of $\mathrm{NO}_{3}{ }^{-}[66]$. The $1 \mathrm{D}$ coordination polymer, $\left[\mathrm{Ag}(\mathrm{edtpn})\left(\mathrm{NO}_{3}\right)\right]_{n}$ (edtpn $=$ ethylenediaminetetrapropionitrile), undergoes anion-dependent rearrangement with recoordination of the $\mathrm{Ag}(\mathrm{I})$ center [67]. During the anion-exchange supramolecular structural transformation between $\left[\mathrm{Ag}(\text { edtpn })\left(\mathrm{NO}_{3}\right)\right]_{n}$, 2D layer $\left\{[\mathrm{Ag}(\text { edtpn })]\left(\mathrm{CF}_{3} \mathrm{SO}_{3}\right)\right\}_{n}$, and box-like 2D network $\left\{[\mathrm{Ag}(\text { edtpn })]\left(\mathrm{ClO}_{4}\right)\right\}_{n}$, are observed in the crystalline state.

The 3D framework of $\left\{\left[\mathrm{Cu}\left(\mathrm{AF}_{6}\right)\left(4,4^{\prime}-\text { bipy }\right)_{2}\right] \cdot x \mathrm{H}_{2} \mathrm{O}\right\}_{n}$ were transformed into a $2 \mathrm{D}$ interpenetrating network of $\left\{\left[\mathrm{Cu}(4,4 \text { '-bipy })_{2}\left(\mathrm{H}_{2} \mathrm{O}\right)_{2}\right] \cdot \mathrm{AF}_{6}\right\}_{n}\left(\mathrm{~A}=\mathrm{Si}\right.$, Ge, and Ti) on being immersed in $\mathrm{H}_{2} \mathrm{O}$ solution [55]. To clarify the occurrence of this dynamic structural transformation in the solid state, $3 \mathrm{D}$ frameworks of $\left\{\left[\mathrm{Cu}\left(\mathrm{AF}_{6}\right)\left(4,4^{\prime} \text {-bipy }\right)_{2}\right] \cdot x \mathrm{H}_{2} \mathrm{O}\right\}_{n}$ were exposed to $\mathrm{H}_{2} \mathrm{O}$ vapor for a few days. The same transformation into a $2 \mathrm{D}$ interpenetration framework was observed, clearly indicating the solid-state conversion. The transformation results from not only the formation and cleavage of weak $\mathrm{Cu}-\mathrm{O}$ and $\mathrm{Cu}-\mathrm{F}$ bonds, but also the formation and cleavage of $\mathrm{Cu}-\mathrm{N}\left(4,4^{\prime}\right.$-bipy) bonds.

Rosseinsky et al. reported two polymorphs of $\mathrm{Ni}(\mathrm{II}), \mathrm{Ni}_{2}(\text { bipy })_{3}\left(\mathrm{NO}_{3}\right)_{4}$ with connected chain structures in which the linear $\mathrm{Ni}$ (bipy) chains are parallel $\left[\mathrm{Ni}_{2}(\text { bipy })_{3}\left(\mathrm{NO}_{3}\right)_{4} \cdot 3 \mathrm{CH}_{3} \mathrm{OH}\right]$ ladder structure or perpendicular $\left[\mathrm{Ni}_{2}(\text { bipy })_{3}\left(\mathrm{NO}_{3}\right)_{4} \cdot 2 \mathrm{C}_{2} \mathrm{H}_{5} \mathrm{OH}\right]$ tongue and groove structure (Fig. 6a) [37]. The methanol-derived ladder $\mathrm{Ni}_{2}$ (bipy) ${ }_{3}$ polymorph, despite its $1 \mathrm{D}$ structure, is robust and microporous above the guest loss temperature due to $\mathrm{C}-\mathrm{H} \cdots \mathrm{O}$ hydrogen-bonding interactions which retain the integrity of the framework structure to $170{ }^{\circ} \mathrm{C}$. Assessment of the diameter of the windows giving access to the porosity shows that they have $50 \%$ of the cross-sectional area of the toluene molecule (Fig. 6b). However, toluene is readily adsorbed by the framework as demonstrated by the coupled thermogravimetric analysis/mass spectroscopy (TGA/MS) experiments, which rule out the uptake of impurities. The system thus couples permanent porosity with flexibility to admit considerably over-sized gueststoluene is appropriately sized to occupy the cavities in the structure as demonstrated by molecular modeling (Fig. 6c). 1,3,5-Triethylbenzene is too large to occupy these cavities and is thus excluded. The windows of the permanently porous metal-organic coordination network thus do not limit the size of the guests which can be adsorbed as long as the guest is of a suitable size and functionality to occupy the cavities. The windows can open to allow the guest access and then close to adsorb it into the cavity. The desolvated framework of ethanol-loaded structure, $\left[\mathrm{Ni}_{2}(\text { bipy })_{3}\left(\mathrm{NO}_{3}\right)_{4} \cdot 2 \mathrm{C}_{2} \mathrm{H}_{5} \mathrm{OH}\right]$, upon exposure to the methanol vapor causes a guest-driven, solid-state structural transformation to the methanoltemplated structure, $\left[\mathrm{Ni}_{2}(\text { bipy })_{3}\left(\mathrm{NO}_{3}\right)_{4} \cdot 3 \mathrm{MeOH}\right]$. This structural rearrangement proceeds directly from the crystalline ethanol-templated structure to the crystalline methanol-templated structure, monitored by PXRD. Mechanism for the transformation is proposed, which requires breaking of at least one in six of the covalent bonds that confer rigidity of the framework.

The crystal structure of $\left\{\left[\mathrm{Fe}_{2}(\mathrm{NCS})_{4}(\text { azpy })_{4}\right] \cdot \mathrm{EtOH}\right\}_{n}$ shows a double interpenetration of $2 \mathrm{D}$ rhombic grids that are connected from Fe(II) and azpy ligands [57]. In the porous network, the guest EtOH molecules are accommodated in the 1D channels, parallel to the $c$-axis. Adsorption and desorption of the guest molecules exhibits structural transformation through the sliding of the interpenetrated layers, which greatly influence the magnetic properties of the compound. The ethanol-desolvated framework does not show spin cross-over, whereas the EtOH- and $\mathrm{MeOH}$-adsorbed compounds undergo a single-step spin cross-over and the 1-propanol-loaded compound undergoes a two-step crossover. 
(a)

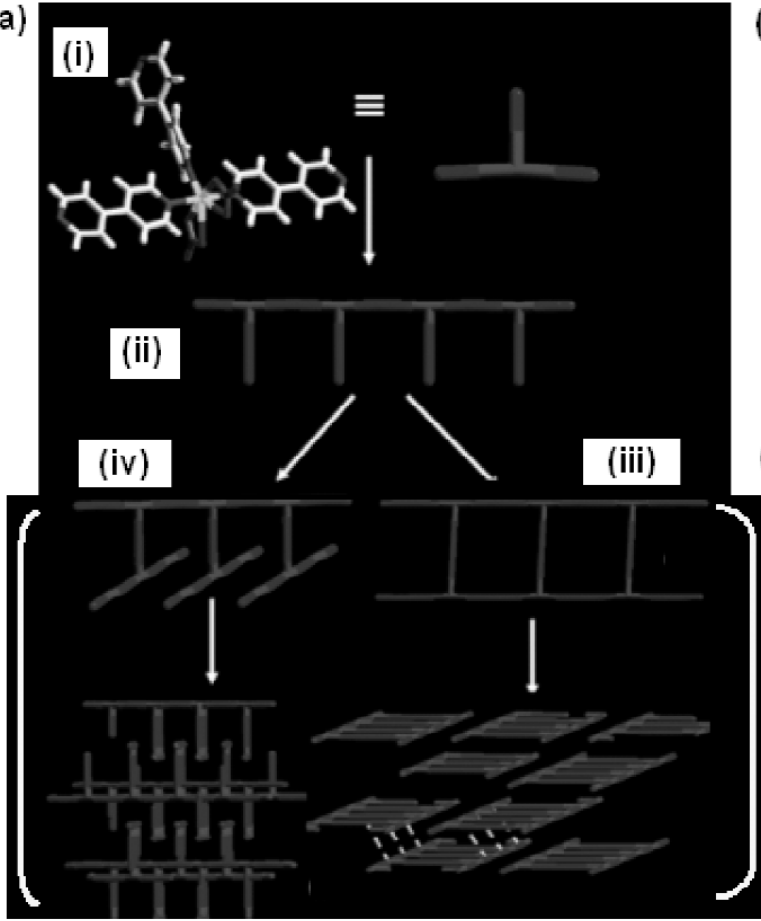

(b)

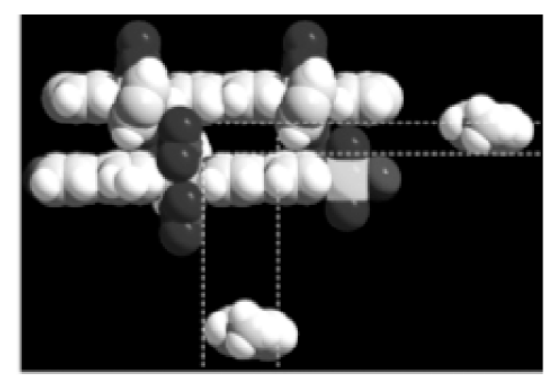

(c)

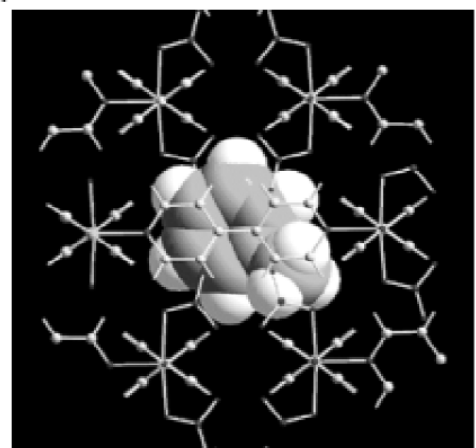

Fig. 6 (a) The coordination of $\mathrm{Ni}$ in two $\mathrm{Ni}_{2}(\text { bipy })_{3}\left(\mathrm{NO}_{3}\right)_{4}$ polymorphs (i) produces a T-shaped node (ii) that produces 1D chain (iii). These chains are assembled by linking via the "cross" of the $\mathrm{T}$ either parallel to give 1D ladder $\left.\left(\mathrm{Ni}_{2} \text { (bipy) }\right)_{3}\left(\mathrm{NO}_{3}\right)_{4} \cdot 3 \mathrm{CH}_{3} \mathrm{OH}\right)$ or (iv) perpendicular to give $\left(\mathrm{Ni}_{2}(\text { bipy })_{3}\left(\mathrm{NO}_{3}\right)_{4} \cdot 2 \mathrm{C}_{2} \mathrm{H}_{5} \mathrm{OH}\right)$ tongue and groove structure; (b) Toluene molecule is sorbed by ladder as the window opens twice to permit access to the cavities; (c) The location of the toluene in the cavity is determined by Monte Carlo docking.

\section{FRAMEWORK INTER-CONVERSION CONTROLLED BY THE HYDROGEN BONDS}

It has recently been demonstrated that certain porous coordination polymers classified as a third generation have a unique characteristic that the porous framework is not robust against the guest removal while it recovers upon the occlusion of guests. Currently, it is not clearly understood whether the forms without guests are amorphous or very poorly crystalline in nature.

A 2D layer motif or 2D bilayer of open framework materials is relevant to create a dynamic porous structure, which exhibits reversible transformation from one form to another, in response to external stimulus. A series of dynamic frameworks were synthesized with layer motifs from $\mathrm{Co}(\mathrm{SCN})_{2}$ and py-amide-py type ligand, like $\mathrm{N}$-3-pyridylisonicotinamide (3-pia), $\mathrm{N}$-3-pyridylnicotinamide (3-pna), and $\mathrm{N}$-(2-pyridine-4-ylethyl)isonicotinamide (4-peia), using the two kinds of hydrogen-bonding interactions as amide-amide and amide-guest [34,51]. The frameworks $\left\{\left[\mathrm{Co}(\mathrm{NCS})_{2}(3-\right.\right.$ pia $\left.\left.)_{2}\right] \cdot 2 \mathrm{EtOH} .11 \mathrm{H}_{2} \mathrm{O}\right\}_{n}, \quad\left\{\left[\mathrm{Co}(\mathrm{NCS})_{2}(3-\text { pia })_{2}\right] \cdot 4 \mathrm{Me}_{2} \mathrm{CO}\right\}_{n}, \quad\left\{\left[\mathrm{Co}(\mathrm{NCS})_{2}(3-\text { pia })_{2}\right] \cdot 4 \mathrm{THF}\right\}_{n}, \quad$ and $\left\{\left[\mathrm{Co}(\mathrm{NCS})_{2}(4-\text { piea })_{2}\right] \cdot 4 \mathrm{Me}_{2} \mathrm{CO}\right\}_{n}$ form similar $2 \mathrm{D}$ layers, however, the mutual relationship between the layers is different, responsible for the different dynamic arrangement. In $\left\{\left[\mathrm{Co}(\mathrm{NCS})_{2}(3-\right.\right.$ pia) $\left.\left.{ }_{2}\right] \cdot 2 \mathrm{EtOH} .11 \mathrm{H}_{2} \mathrm{O}\right\}_{n}, \mathrm{Co}$ (II) ions are linked by the 3-pia ligands to form a $2 \mathrm{D}$ sheet and EtOH molecules are trapped by hydrogen-bonding with amide moiety. The adjacent sheets are stacked offset with respect to each other, in an $\mathrm{ABAB}$ fashion. The framework cannot withstand the high level of stress on the extensive loss of guests, resulting in an amorphous structure (Fig. 7a) [34]. A similar behavior, crystal-to-amorphous transformation, is observed for $\left\{\left[\mathrm{Co}(\mathrm{NCS})_{2}(4-\text { piea })_{2}\right] \cdot 4 \mathrm{Me}_{2} \mathrm{CO}\right\}_{n}$ after the removal of acetone molecules, which are accommodated in the pore without any significant interaction (Fig.7b) 

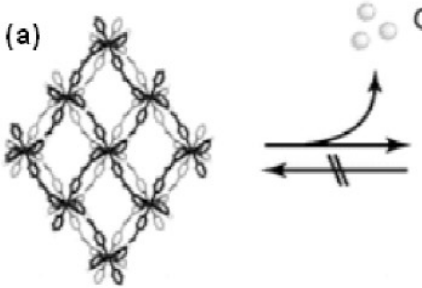

(c)

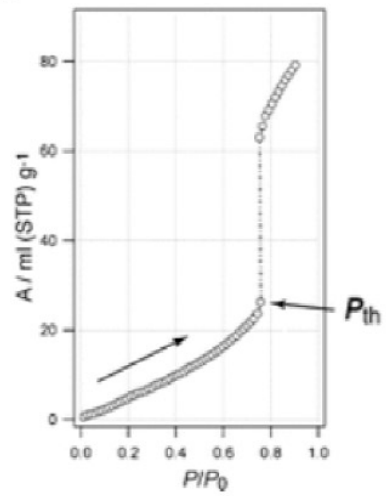

Guest

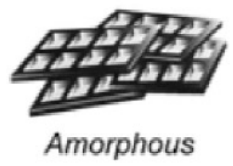

Amorphous (b)

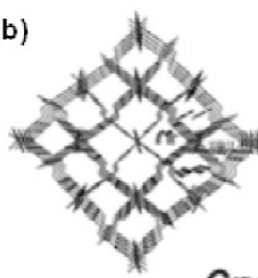

Crystal-to-Amorphous
Guest

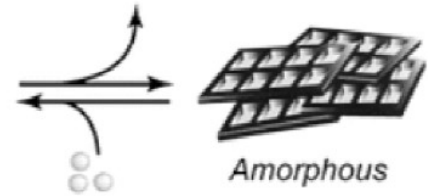

(d)

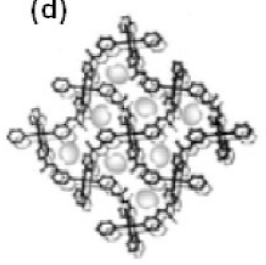

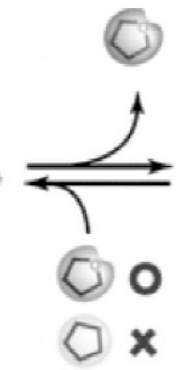

Crystal-to-Crystal

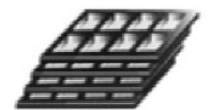

Selective Sorption

Fig. 7 Schematic view of the crystal-to-amorphous transformation found in (a) $\left\{\left[\mathrm{Co}(\mathrm{NCS})_{2}(3-\right.\right.$ pia) $\left.\left.{ }_{2}\right] \cdot 2 \mathrm{EtOH} .11 \mathrm{H}_{2} \mathrm{O}\right\}_{n}$; (b) $\left\{\left[\mathrm{Co}(\mathrm{NCS})_{2}(4 \text {-piea) })_{2}\right] \cdot 4 \mathrm{Me}_{2} \mathrm{CO}\right\}_{n}$; (c) Isotherm for acetone vapor adsorption (open circles) at $298 \mathrm{~K} \mathrm{in}\left\{\left[\mathrm{Co}(\mathrm{NCS})_{2}(4 \text {-piea })_{2}\right]_{n}\right.$ over the pressure range from 0.507 to $27.756 \mathrm{kPa}$. $P_{0}$ is the saturated vapor pressure, $30.593 \mathrm{kPa}$ of acetone at $298 \mathrm{~K}$; (d) Schematic view of the crystal-to-crystal transformation in certain solvent guests in $\left\{\left[\mathrm{Co}(\mathrm{NCS})_{2}(3-\text { pia })_{2}\right] \cdot 4 \mathrm{THF}\right\}_{n}$.

[51]. The characteristic adsorption profile with $\mathrm{Me}_{2} \mathrm{CO}$ clearly indicates that upon the conversion of the amorphous to the crystalline form, a certain threshold pressure $\left(P_{\mathrm{th}}\right)$ is required to start the corresponding reaction (Fig. 7c). In $\left\{\left[\mathrm{Co}(\mathrm{NCS})_{2}(3-\text { pia })_{2}\right] \cdot 4 \mathrm{THF}\right\}_{n}$, THF molecules are trapped in the cavity by hydrogen bonds and removal of the THF molecules affords new crystalline sheets and the original crystal structure returns upon exposure to the THF vapor (Fig. 7d) [34]. This mechanism is attributed to the arrangement of the adjacent layers so suited in regularity that the hydrogen bond pillar frameworks form efficiently; namely, "amide-guest" to "amide-amide" hydrogen bond transformation. This new type of layer crystals paves the way to the selective inclusion system reflecting the size/shape and hydrogenbonding capability; similarly, THF can be adsorbed while cyclopentane is not.

$\left\{\left[\mathrm{Zn}(\mathrm{bdc})\left(\mathrm{H}_{2} \mathrm{O}\right)\right] \cdot \mathrm{dmf}\right\}_{n}$ shows a $2 \mathrm{D}$ layer of dimeric $\mathrm{Zn}(\mathrm{II})$ units with terminally coordinated water molecules which are further hydrogen-bonded to guest molecules and the desolvated form $[\mathrm{Zn}(\mathrm{bdc})]_{n}$ forms new crystalline structure [46]. The reverse reaction results from the adsorption of water molecules, which is ascribed to the hydrogen-bond formation and also transformed to a diverse array of structures depending on the nature of the hydrogen-bonding guest. 2-Tert-butylphenol is too large to be accommodated in the micropores, and, therefore, the framework is deformed for the guests occlusion.

A sponge-like $2 \mathrm{D}$ honeycomb coordination network $\left\{\left[\mathrm{Cu}_{3}(\mathrm{PTMTC})_{2}(\mathrm{py})_{6}(\mathrm{EtOH})_{2}\left(\mathrm{H}_{2} \mathrm{O}\right)\right]\right.$ $\left.10 \mathrm{EtOH} .6 \mathrm{H}_{2} \mathrm{O}\right\}_{n}$ was reported by Veciana et al., by exploiting the bridging potential of a radical bridging ligand, PTMTC (polychlorinated triphenylmethyl with three carboxyl groups) [33]. Each 2D layer structure undergoes weak $\pi-\pi$ and van der Waals interactions forming $3 \mathrm{D}$ open framework structure. The guest ethanol and water molecules are hydrogen-bonded with the coordinated water molecules. Upon being exposed to air, the single crystal lost the solvent molecules very rapidly at room temperature and open atmosphere, becoming an amorphous material with a drastic decrease in size. The structural integrity and size completely recovered when desolvated crystal re-immersed in liquid ethanol, in- 
dicating solvent-induced "shrinking-breathing" process, which strongly influences the magnetic properties.

\section{DYNAMIC FRAMEWORK WITH TWO DIFFERENT PHASES: GATE-OPENING AND -CLOSING PHENOMENON}

The flexibility of coordination frameworks has been exploited to produce the porosity using the guest pressure. By utilizing structural flexibility, we could realize pressure-responsive gated sorption even in a case that a nonporous phase is transformed to the corresponding porous phase in a certain vapor pressure. The background for this contrivance is bond breaking/formation, the rotation of covalent bond, and so on.

The flexible and dynamic microporous frameworks based on 2D interdigitation, $\left\{\left[\mathrm{Cu}\left(4,44^{\prime}-\right.\right.\right.$ bipy $\left.\left.)(\mathrm{dhbc})_{2}\right] \cdot \mathrm{H}_{2} \mathrm{O}\right\}_{n}($ CPL-p1) (dhbc $=2,5$-dihydroxy benzoate) and 3D interpenetrated $\{[\mathrm{Cu}(1,4-$ bdc) $\left.\left.(4,4 \text { '-bipy })_{0.5}\right]\right\}_{n}$ (CPL-v1) have been synthesized [36]. The PXRD pattern of the dehydrated CPL-p1 shows a drastic change from the as-synthesized framework, and synchrotron PXRD shows a cell parameter change on dehydration, which corresponds to a cell volume contraction of $27 \%$. This structural transformation of CPL-p1, especially the change of the lengths along the $c$-axis, is accompanied by a shrinking of the interlayer distance, attributable to a glide motion of two $\pi$-stacked ring moieties of dhbc, which results in the decrease of a channel cross-section. CPL-p1 shows characteristic hysteretic adsorption isotherms, which have gate-opening and -closing pressure for $\mathrm{CO}_{2}$ vapor and various supercritical gases $\left(\mathrm{CH}_{4}, \mathrm{O}_{2}\right.$, and $\left.\mathrm{N}_{2}\right)$. This characteristic adsorption behavior should be attributed to crystal structure expansion and contraction triggered by gas adsorption and desorption, as confirmed by an PXRD study. CPL-v1 also shows similar adsorption isotherms, which result from slipped motion of interpenetrated networks.

A novel 3D pillared-layer structure of $\mathrm{Cu}(\mathrm{II}),\left\{\left[\mathrm{Cu}_{2}(\mathrm{pzdc})(\mathrm{dpyg})\right] \cdot 8 \mathrm{H}_{2} \mathrm{O}\right\}_{n}(\mathrm{dpyg}=1$, 2-dipyridylglycol) shows reversible crystal-to-crystal transformation on adsorption and desorption of $\mathrm{H}_{2} \mathrm{O}$ or $\mathrm{MeOH}$ molecules [35]. Upon dehydration, the 3D framework undergoes contraction in the channel size and structure determination from the high-resolution synchrotron PXRD shows that the layer-layer separation drastically reduces to $9.6 \AA$ from $13.2 \AA$ in the as-synthesized framework and unit cell volume decreases during the contraction by $27.9 \%$ (Fig. 8a). This drastic structural change influences the sorption properties, which shows that $\mathrm{N}_{2}$ and $\mathrm{CH}_{4}$ cannot diffuse into the micropore but $\mathrm{H}_{2} \mathrm{O}$ and $\mathrm{MeOH}$ can go inside into the framework, although the size of the cross-section is smaller than the $\mathrm{MeOH}$ molecule. The sorption isotherm shows that $\mathrm{MeOH}$ sorption takes place at a certain relative vapor pressure $\left(P / P_{0}=0.23\right)$, called gate-opening pressure, and the desorption curve does not trace the adsorption one, resulting in large hysteresis. This corroborates a structural transformation (Fig. 8b), chiefly associated with the hydrogen-bonding interaction with the $\mathrm{OH}$-group of the functional pillar module, dpyg, which is the driving force for gate-opening toward the specific guest molecules.

The dynamic porous 2D layers, $\left\{\left[\mathrm{Cu}\left(4,4^{\prime} \text {-bipy }\right)\left(\mathrm{BF}_{4}\right)_{2}\left(\mathrm{H}_{2} \mathrm{O}\right)_{2}\right] \cdot 4.4^{\prime} \text {-bipy }\right\}_{n}$, show unique adsorption and magnetic properties having cavities of a cross-sectional area of $7.7 \times 11.6 \AA^{2}$ [54]. The 4,4'-bipy ligand provides bimodal functions, with one bridging the two $\mathrm{Cu}$ centers by direct coordination while the other links $\mathrm{Cu}$ atoms by hydrogen bond via coordinated water molecules. The 2D layers are in staggered conformation, which obstructs the accommodation of guest molecules in the pores. However, the adsorption of $\mathrm{N}_{2}, \mathrm{Ar}$, and $\mathrm{CO}_{2}$ is observed at certain relative pressure with pressure-induced opening of the pore. This phenomenon was regulated by the hydrogen-bonding interactions between the adsorbates and pores surface of the adsorbent. 


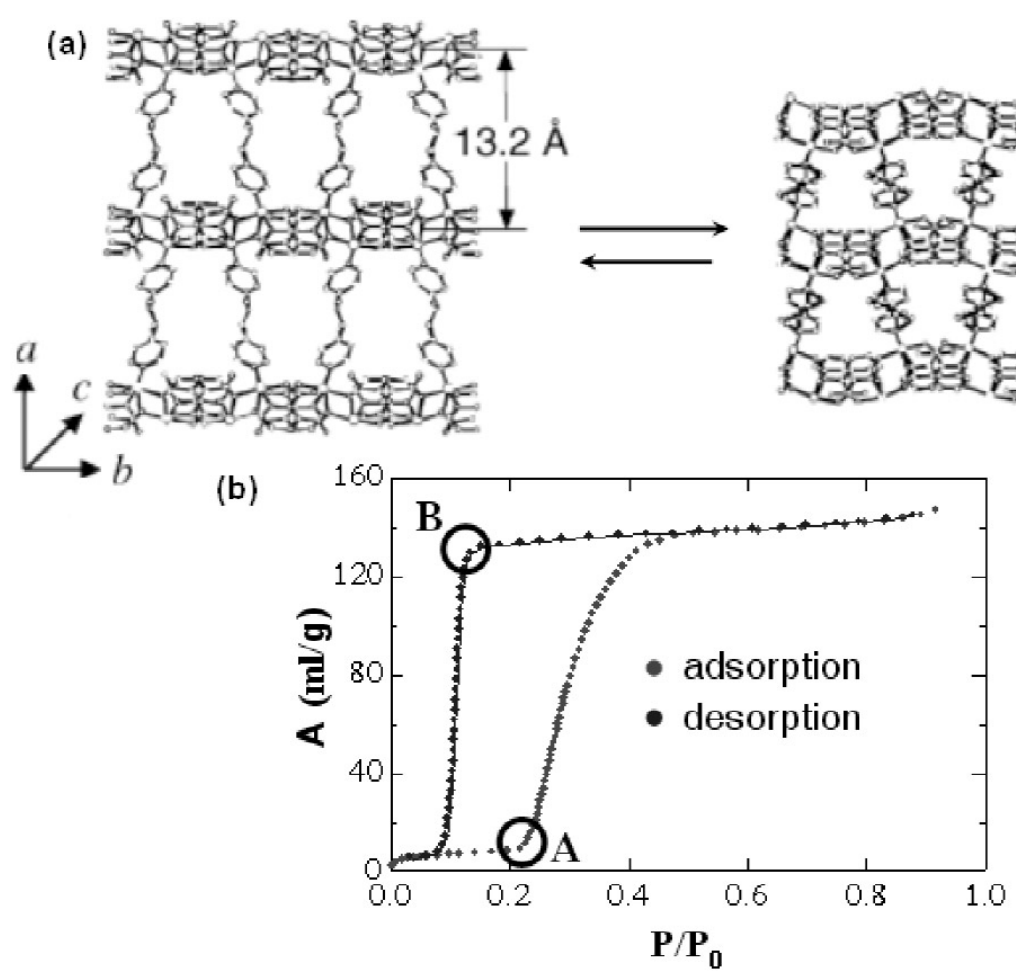

Fig. 8 (a) Reversible crystal-to-crystal structural transformation in $\left\{\left[\mathrm{Cu}_{2}(\mathrm{pzdc})_{2}(\mathrm{dpyg})\right] \cdot 8 \mathrm{H}_{2} \mathrm{O}\right\}_{n}$ involving the expansion and contraction of the channel by adsorption and desorption of $\mathrm{H}_{2} \mathrm{O}$ and $\mathrm{MeOH}$ molecules; (b) $\mathrm{MeOH}$ adsorption isotherm at $298 \mathrm{~K}$.

Recently, a novel porous framework of $\mathrm{Cu}(\mathrm{II}),\left\{[\mathrm{Cu}(2,3 \text {-pyrdc })(\mathrm{bpp})]\left(5 \mathrm{H}_{2} \mathrm{O}\right)\right\}_{n}(2,3$-pyrdc $=$ pyridine-2,3-dicarboxylate, $\mathrm{bpp}=1,3$-bis(4-pyridyl)propane) has been synthesized and structurally characterized, which has a 2D honeycomb-like bilayer pillared network with 3D water-filled channel [58]. The 2D-bilayer framework shows single-crystal-to-single-crystal structural transformation with centric-toacentric-to-centric upon dehydration and rehydration (Fig. 9a). Upon dehydration, as-synthesized centric blue crystal undergoes bond breaking to generate acentric crystal where one of the pendent bpp ligand protrudes to the groove of the channel resulting in the nonporous phase. The nonporous phase, when subjected to sorption studies with the different adsorbates, shows that $\mathrm{CO}_{2}, \mathrm{MeOH}$, and $\mathrm{EtOH}$ molecules can be adsorbed into the framework at certain pressure, which is termed as "gate-opening pressure", but in the case of $\mathrm{N}_{2}$ and $\mathrm{O}_{2}$, no such phenomenon is observed (Fig. 9b). Every sorption profile shows a sudden adsorption jump and desorption drops with large hysteresis and without coincidence, indicating the framework transformation. The threshold pressure at which the gate-opening depends upon the adsorbate, like $\mathrm{MeOH}$ sorption, started at $P / P_{0}=0.09$ and for $\mathrm{CO}_{2}$ and EtOH $P / P_{0}=$ 0.23 (Fig. 9b). This is chiefly associated with the different hydrogen-bonding interaction of the adsorbate and apohost. The determination of the single-crystal structure with occlusion of $\mathrm{CO}_{2}$ molecules into the frameworks shows that two $\mathrm{CO}_{2}$ molecules accommodated into the framework correlate with the sorption experiment (Fig. 9c). The $\mathrm{CO}_{2}$ molecules undergo $\mathrm{C}-\mathrm{H} \cdots \mathrm{O}$ hydrogen-bonding interaction with the pore wall, which is the driving force for occlusion into the framework in comparison with the $\mathrm{O}_{2}$ and $\mathrm{N}_{2}$. 
(a)
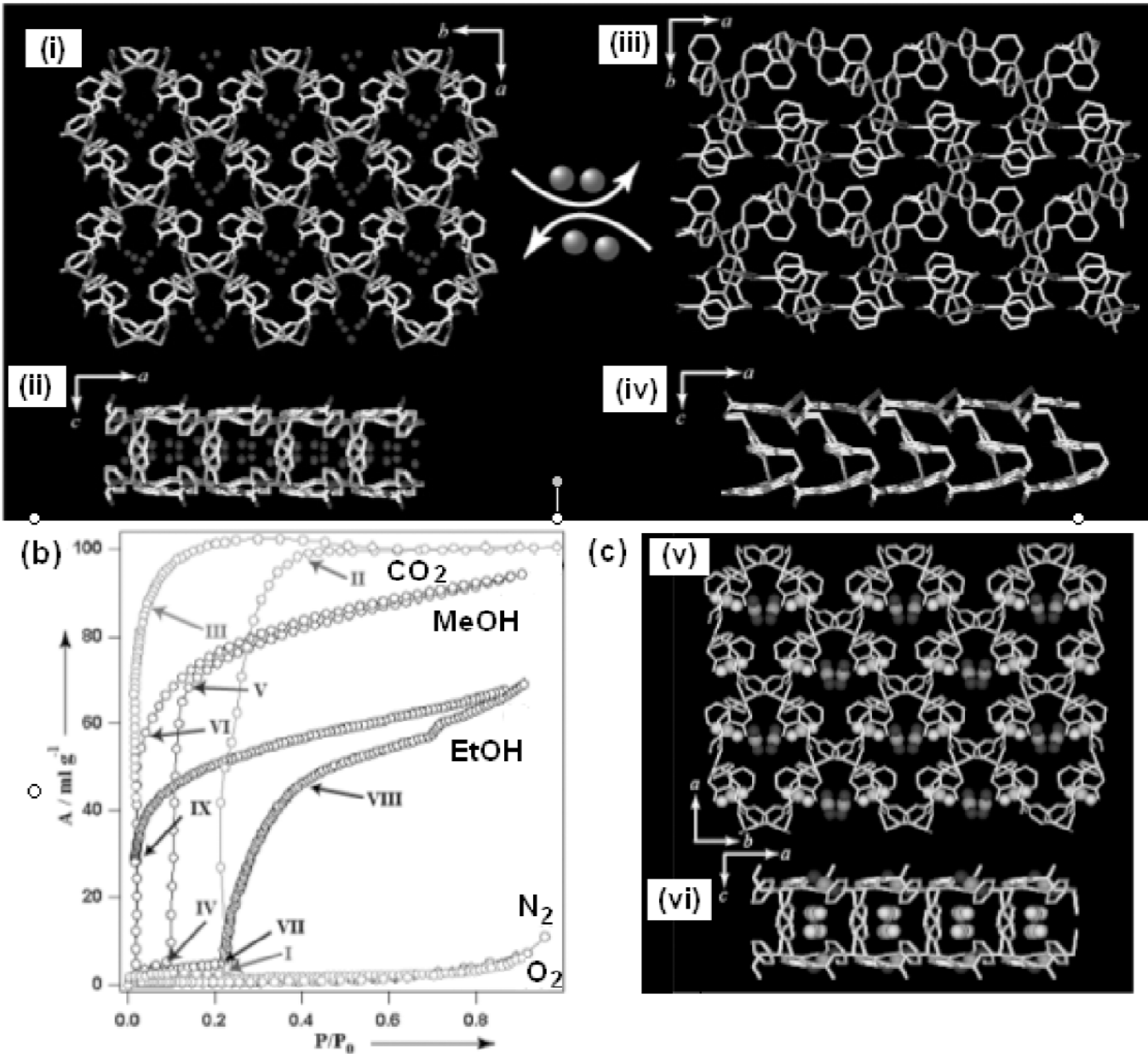

(c)

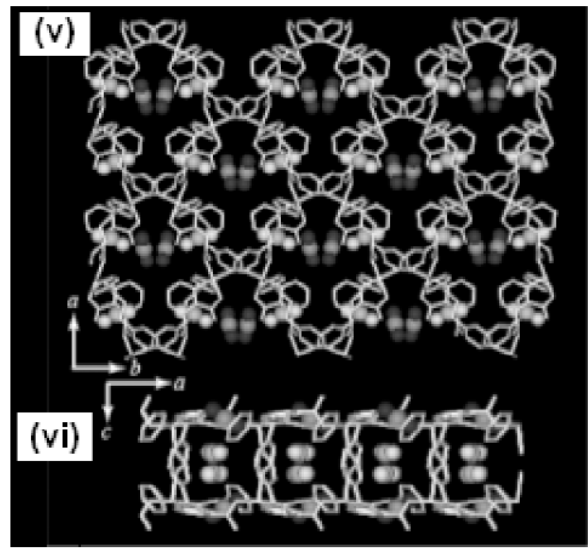

Fig. 9 (a) Structure of $\left\{\left[\mathrm{Cu}(2,3-\text { pyrdc) }(\mathrm{bpp})]\left(5 \mathrm{H}_{2} \mathrm{O}\right)\right\}_{n}\right.$ (i) Honeycomb-like 2D layers showing a water-filled channel along the $c$-axis, (ii) Pillared-bilayer network showing the channel along the $b$-axis. Structure of dehydrated $\left[\mathrm{Cu}_{2}(2,3-\text { pyrdc })_{2}(\mathrm{bpp})_{2}\right]_{n}$, (iii) Honeycomb-like 2D layers along the $c$-axis. (iv) Pillared-bilayer network along the $b$-axis (the pendent bpp ligand is occupied in the channel); (b) Sorption isotherm for different adsorbate in dehydrated framework (where $P / P_{0}$ is the relative vapor pressure); (c) (v) Honeycomb-like 2D layer with $\mathrm{CO}_{2}$ molecules along the $c$-axis, (vi) Pillared-bilayer network along the $b$-axis with $\mathrm{CO}_{2}$ molecules.

\section{DYNAMIC FRAMEWORK WITH SINGLE-CRYSTAL-TO-SINGLE-CRYSTAL TRANSFORMATION: GUEST REMOVAL AND GUEST EXCHANGE}

There are examples of successful determination of the single-crystal structure of the porous framework in desolvated state $[26,32,68,69]$. In many rigid frameworks, loosely bound guest molecules can be removed from the framework without affecting the single crystallinity, affording the apohost with permanent porosity for other molecules. Recently, several examples have been reported that frameworks can exchange guest molecules with retention of the single crystallinty.

A bilayer open framework, $\left[\mathrm{Ni}_{2}\left(\mathrm{C}_{26} \mathrm{H}_{52} \mathrm{~N}_{10}\right)\right]_{3}[\mathrm{BTC}]_{4} \cdot 6 \mathrm{C}_{5} \mathrm{H}_{5} \mathrm{~N} \cdot 36 \mathrm{H}_{2} \mathrm{O}$ (BOF-1), has been obtained from Ni(II)-bis-macrocylic complex, $\left[\mathrm{Ni}_{2}\left(\mathrm{C}_{26} \mathrm{H}_{52} \mathrm{~N}_{10}\right)(\mathrm{Cl})_{4}\right] \cdot \mathrm{H}_{2} \mathrm{O}$ and BTC [41]. The framework have 2D layers with brick-wall motif pillared by the $p$-xylyl groups of the bis-macrocycle, creates 3D channels with $61 \%$ void space of the total crystal volume (Fig. 10a). When the as-synthesized crystal heated at $75{ }^{\circ} \mathrm{C}$ results in the formation of $\left[\mathrm{Ni}_{2}\left(\mathrm{C}_{26} \mathrm{H}_{52} \mathrm{~N}_{10}\right)\right]_{3}[\mathrm{BTC}]_{4} \cdot 4 \mathrm{H}_{2} \mathrm{O}$, where no practical 
(a)

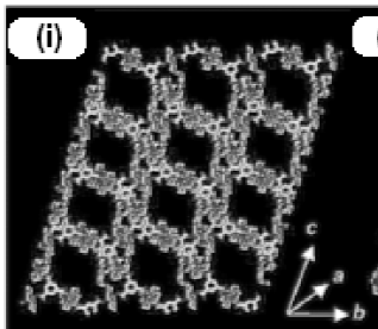

(ii)

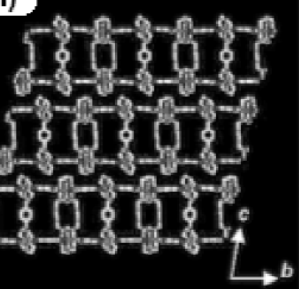

(b)

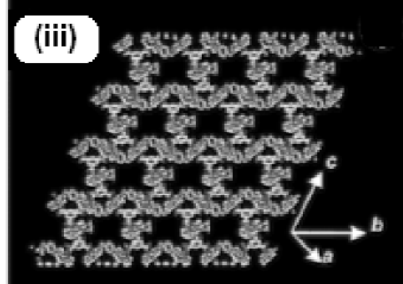

(iv)
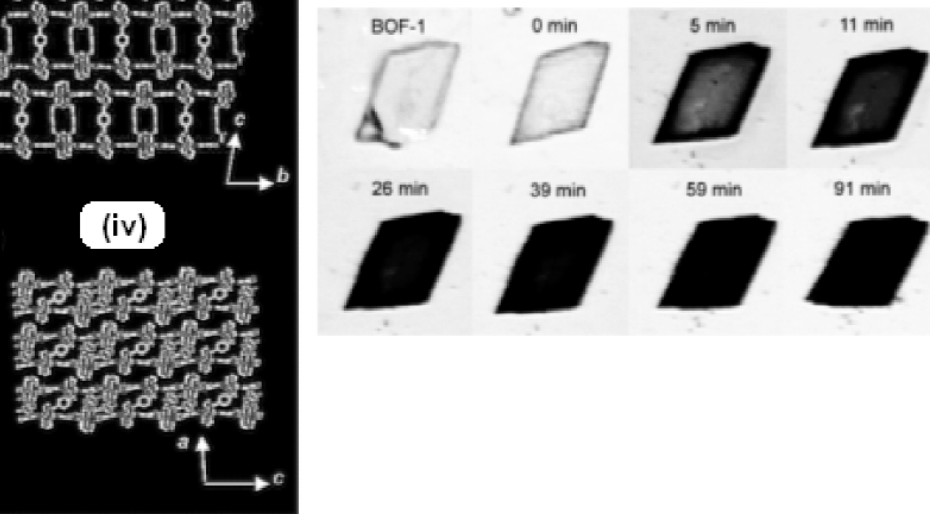

$26 \mathrm{~min}$

$39 \mathrm{~min}$

59 min

$91 \mathrm{~min}$
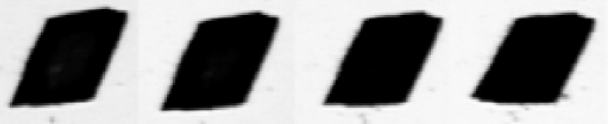

(c)

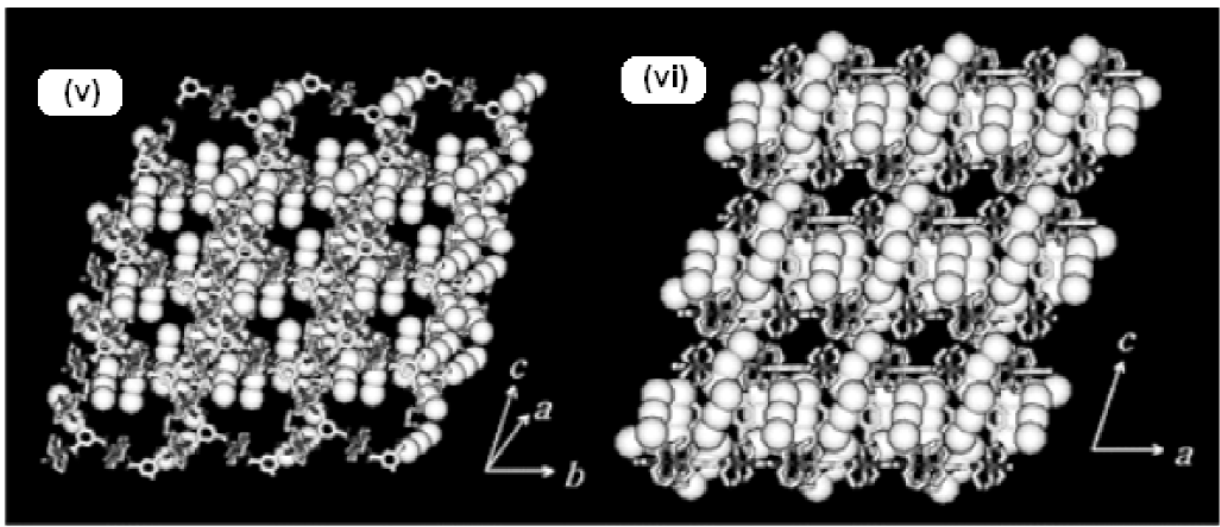

Fig. 10 (a) X-ray structures of BOF-1. (i) Top view showing 2D layers of brick-wall motif, (ii) Side view showing pillared-bilayer structure, (iii) Top view of desolvated crystal, (iv) Side view showing tilted pillars; (b) Photographs showing progress of the redox reaction when a crystal BOF-1 was immersed in the DMSO/ $\mathrm{H}_{2} \mathrm{O}$ solution of $\mathrm{I}_{2}$. The photographs of the crystal showed no further change in color and morphology after $90 \mathrm{~min}$; (c) Structure of BOF-1, showing oxidized framework with $\mathrm{I}_{3}{ }^{-}$and $\mathrm{I}_{2}$ included in the channels. (v) Top view, (vi) Side view.

change was observed in the 2D layers but the thickness of the bilayer was greatly reduced to 6.82(2) $\bar{A}$ from 11.91(1) $\AA$ due to the significant tilting of the pillars (Fig. 10a). The reversibility was confirmed by exposing the single crystal of $\left[\mathrm{Ni}_{2}\left(\mathrm{C}_{26} \mathrm{H}_{52} \mathrm{~N}_{10}\right)\right]_{3}[\mathrm{BTC}]_{4} \cdot 4 \mathrm{H}_{2} \mathrm{O}$ in water-pyridine vapor, and this compound also differentiates the various alcohols in toluene. Most interestingly, the guest-exchange process was observed upon putting the single crystal of the as-synthesized compound in benzene, forming $\left[\mathrm{Ni}_{2}\left(\mathrm{C}_{26} \mathrm{H}_{52} \mathrm{~N}_{10}\right)\right]_{3}[\mathrm{BTC}]_{4} \cdot 14 \mathrm{C}_{6} \mathrm{H}_{6} \cdot 19 \mathrm{H}_{2} \mathrm{O}$. These results show sponge-like dynamic behavior with single-crystal-to-single-crystal transformation, reducing the interlayer spacing dramatically in response to the amount of guest removal as well as retention of single crystallinity with the guest exchange. Later, the redox reactions have been carried out by immersing the single crystal in $\mathrm{DMSO} / \mathrm{H}_{2} \mathrm{O}(1: 1,2 \mathrm{ml})$ solution of $\mathrm{I}_{2}$ [48], which showed that the color of the crystal changed from the light pink to dark brown (Fig. 10b). The redox reaction between the crystal and $\mathrm{I}_{2}$ occurs quantitatively to form $\left[\mathrm{Ni}_{2}\left(\mathrm{C}_{26} \mathrm{H}_{52} \mathrm{~N}_{10}\right)\right]_{3}[\mathrm{BTC}]_{4} \cdot\left(\mathrm{I}_{3}\right)_{4} \cdot n \mathrm{I}_{2} \cdot 17 \mathrm{H}_{2} \mathrm{O}(n=5$ based on the elemental analysis and magnetic susceptibility). By the reaction with $\mathrm{I}_{2}$, two-thirds of the $\mathrm{Ni}(\mathrm{II})$ ions contained in the framework were oxidized to low-spin $\mathrm{Ni}(\mathrm{III})$, and the $\mathrm{I}_{2}$ molecules were reduced to $\mathrm{I}_{3}{ }^{-}$anions, which were included in the channels of the framework (Fig. 10c). 
A stable, non-interpenetrated square grid framework was obtained from a long bipyridyl-type pillar ligand, 4,4'-di(4-pyridyl)biphenyl, with $\mathrm{Ni}\left(\mathrm{NO}_{3}\right)_{2}$, forming $\left\{\left[\mathrm{Ni}(\mathrm{L})\left(\mathrm{NO}_{3}\right)_{2}\right] \cdot 4(o \text {-xylene })\right\}_{n}$ and $\left\{\left[\mathrm{Ni}(\mathrm{L})\left(\mathrm{NO}_{3}\right)_{2}\right] \cdot 5\left(\mathrm{C}_{6} \mathrm{H}_{6}\right) \cdot 2\left(\mathrm{CH}_{3} \mathrm{OH}\right)\right\}_{n}$ in methanol and $o$-xylene, methanol, and benzene, respectively [38]. In $\left\{\left[\mathrm{Ni}(\mathrm{L})\left(\mathrm{NO}_{3}\right)_{2}\right] \cdot 4(o \text {-xylene })\right\}_{n}, 2 \mathrm{D}$ grids packed in a staggered manner form a rectangular channel running orthogonal to the layers, and were occupied by an ordered array of the $o$-xylene molecules. The framework retained its integrity up to $300{ }^{\circ} \mathrm{C}$ with the single crystallinity, and structure determination shows slight readjustment of the framework. Interestingly, the framework can exchange the $o$ xylene guest molecules with mesitylene by the immersion of the single crystal for $6 \mathrm{~h}$, and structure determination shows that dramatic sliding of the layers over each other, which is accompanied by the much wider channel than in the original, where 1.7 mesitylene molecules were incorporated per $\mathrm{Ni}(\mathrm{II})$, $\left\{\left[\mathrm{Ni}(\mathrm{L})\left(\mathrm{NO}_{3}\right)_{2}\right] \cdot 1.7 \text { (mesitylene) }\right\}_{n}$. Single-crystal data collection in the mesitylene environment suggests crystal-to-crystal transformation rather than dissolution and recrystaliization.

A compound of $\left\{\left[\mathrm{Co}(\mathrm{L})_{2}\left(\left(\mathrm{H}_{2} \mathrm{O}\right)_{2}\right]\left(\mathrm{NO}_{3}\right)_{2}\left(1.5 \mathrm{H}_{2} \mathrm{O}\right)\right\}_{n}(\mathrm{~L}=4,4\right.$ '-di(4-pyridyl)biphenyl with ethylene glycol side chains) has been synthesized, which has a square grid-type framework with two coordinate water molecules on apical position and two $\mathrm{NO}_{3}$ and $1.5 \mathrm{H}_{2} \mathrm{O}$ molecules in the pore [40]. Upon heating at $150{ }^{\circ} \mathrm{C}$ for $24 \mathrm{~h}$, the yellow as-synthesized crystal turned red, and structure determination reveals that the apical water molecules had been substituted by two nitrate anions and upon exposure to the water vapor original structure was regenerated. This shows reversible single-crystal-to-single-crystal transformation with breaking and reformation of the apical covalent bond. The chromism in the crystal is described by the apical ligand exchange.

Single-crystal-to-single-crystal structural transformation in a 3D porous doubly interpenetrated $\mathrm{Zn}$ (II) based framework, $\left\{\left[\left(\mathrm{ZnI}_{2}\right)_{3}(\mathrm{tpt})_{2}\right]\right\}$ was observed, which had continuous channels occupied by either nitrobenzene or cyanobenzene molecules, depending on solvents in the synthesis (Fig. 11a) [39]. A significant change occurs by desolvation of yellow crystal, accompanying reduction in volume $20-23 \%$ and also associated with reduction of inter-network metal-metal separation. Re-immersion of this desolvated condensed framework in nitrobenzene regenerated a solvent-filled expanded framework.

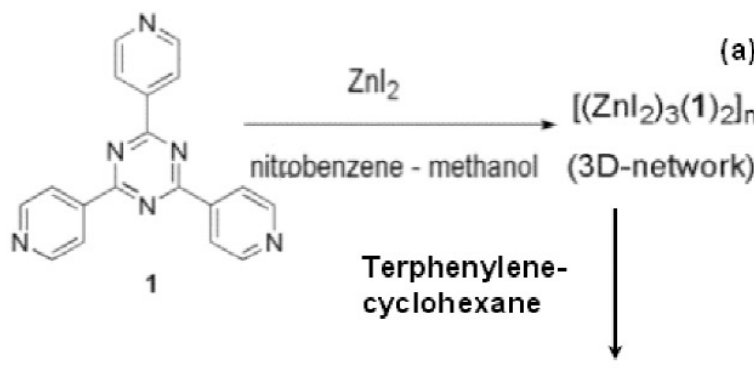

(b)

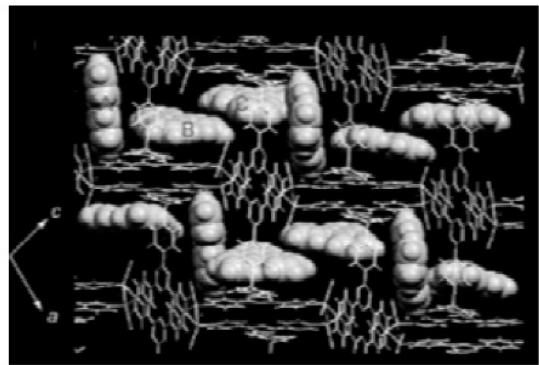

(a)

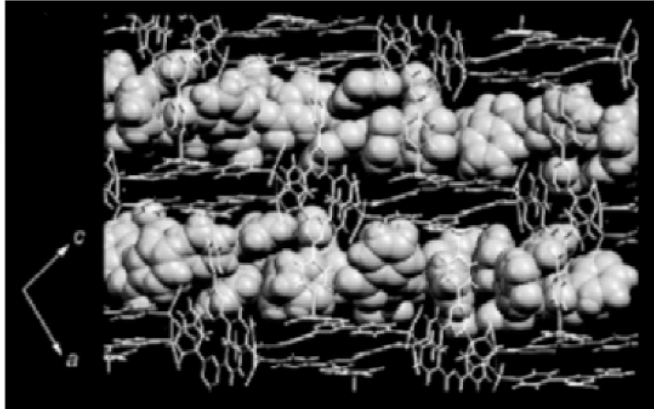

(c)

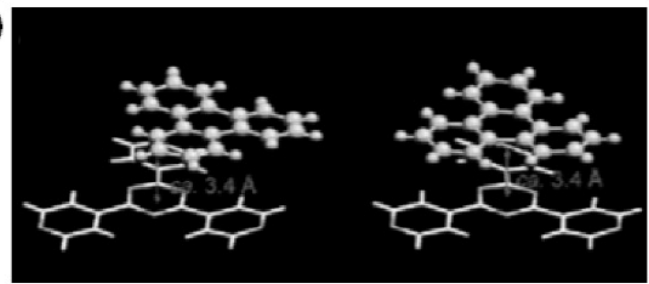

Fig. 11 (a) View of the structure $\left\{\left[\left(\mathrm{ZnI}_{2}\right)_{3}(\mathrm{~L})_{2}\right] .5 .5\right.$ (nitrobenzene) $\}[\mathrm{L}=2,4,6$-tri(4-pyridyl)triazine $]$ accommodating nitrobenzene molecules; (b) After guest exchange with triphenylene molecules without change of the framework, $\left\{\left[\left(\mathrm{ZnI}_{2}\right)_{3}(\mathrm{~L})_{2}\right] \cdot 1.5\right.$ (triphenylene) $\cdot 2.5$ (cyclohexane); (c) Views of the $\pi-\pi$ interaction between the ligand $\mathbf{1}$ and triphenylene. 
When the nitrobenzene clathrate, $\left\{\left[\left(\mathrm{ZnI}_{2}\right)_{3}(\mathrm{tpt})_{2}\right] \cdot 5.5 \text { (nitrobenzene) }\right\}_{n}$ was immersed in a saturated cyclohexane solution of triphenylene, anthracene, and perylene for $24 \mathrm{~h}$ at room temperature, the crystal color was changed without change in the size and morphology [70]. The crystallographic studies shows that the structure of the inclusion complexes $\left\{\left[\left(\mathrm{ZnI}_{2}\right)_{3}(\mathrm{tpt})_{2}\right] \cdot 1.5 \text { (triphenylene) } \cdot 2.5 \text { (cyclohexane) }\right\}_{n}$ (Fig. 11b), $\left\{\left[\left(\mathrm{ZnI}_{2}\right)_{3}(\mathrm{tpt})_{2}\right] \cdot 1.4(\text { anthracene }) \cdot 2.2(\text { cyclohexane })\right\}_{n}$ and $\left\{\left[\left(\mathrm{ZnI}_{2}\right)_{3}(\mathrm{tpt})_{2}\right] \cdot(\right.$ perylene $) \cdot($ cyclohexane) $\}_{n}$, where nitrobenzene is exchanged with the large organic templates and the close ligand-guest contact suggests that donor-acceptor interaction between the electron-rich guest and the electron-deficient ligand, with significant color change (Fig. 11c). The inclusion of large guest took place in a dynamic fashion.

Homochiral, porous metal-organic networks are particularly attractive candidates as heterogeneous asymmetric catalysts for the economical production of optically active organic compounds. This function is not possible by achiral inorganic zeolites [15,21,71]. Several chiral microporous MOFs with potential application in asymmetric catalysis have been synthesized by Lin et al. [15,71]. Recently, they have successfully constructed a homochiral $1 \mathrm{D}$ chain of $\mathrm{Cd}(\mathrm{II}),\left[\mathrm{CdL}_{2}\left(\mathrm{ClO}_{4}\right)_{2}\right] \cdot 11 \mathrm{EtOH} \cdot 6 \mathrm{H}_{2} \mathrm{O}$, where $\mathrm{L}=(S)$-2,2'-diethoxy-1,1'-binaphthyl-6,6'-bis(4-vinylpyridine) and all the 1D chains lie parallel to each other forming layer structure (Fig. 12a) [72]. The 1D chains of the adjacent layers are packed by $120^{\circ}$ with respect to each other, forming chiral 1D pseudo-hexagonal channel occupied by the water and EtOH molecules. The permanent porosity was confirmed by the $\mathrm{CO}_{2}$ sorption studies. The most interesting observation is the reversible single-crystal-to-single-crystal transformation upon exchange with different guest molecules. The as-synthesized crystal upon exposing with $\mathrm{C}_{6} \mathrm{H}_{6}$ vapor shows time-dependent exchange of $\mathrm{C}_{6} \mathrm{H}_{6}$ with $\mathrm{EtOH}$, and after more than $24 \mathrm{~h}$, complete exchange occurs (Fig. 12b). For the $\mathrm{C}_{6} \mathrm{H}_{6}$-exchanged crystals $\left[\mathrm{CdL}_{2}\left(\mathrm{ClO}_{4}\right)_{2}\right] \cdot 6 \mathrm{C}_{6} \mathrm{H}_{6} \cdot \mathrm{H}_{2} \mathrm{O}$, when exposed to EtOH vapors, the $\mathrm{C}_{6} \mathrm{H}_{6}$ molecules are exchanged with $\mathrm{EtOH}$ with varying the time showing reversibility of the single-crystal-to-single-crystal transformation (Fig. 12b).

(a)

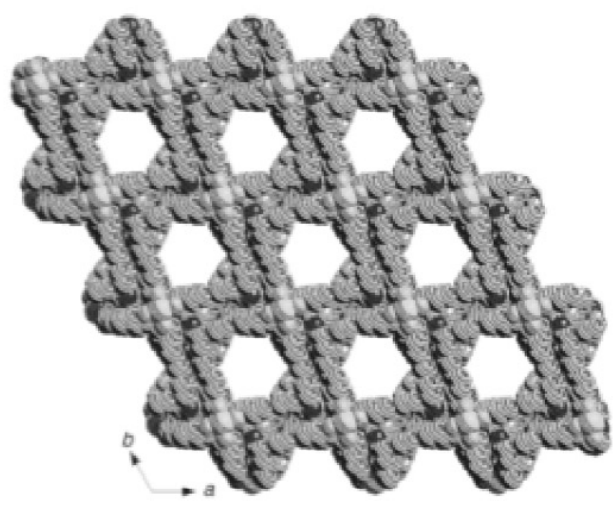

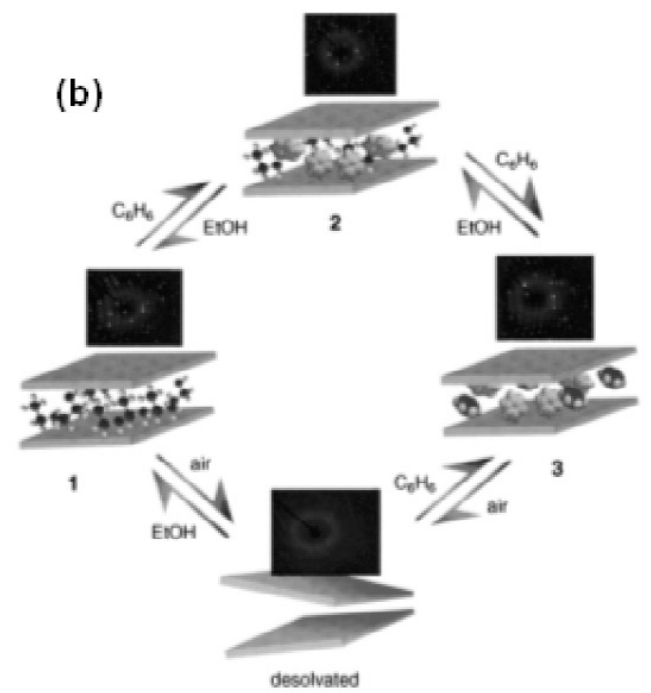

Fig. 12 (a) Space-filling representation of $\left[\mathrm{CdL}_{2}\left(\mathrm{ClO}_{4}\right)_{2}\right] \cdot 11 \mathrm{EtOH} \cdot 6 \mathrm{H}_{2} \mathrm{O}$ with chiral 1D hexagonal channel; (b) Schematic representation of the reversible single-crystal-to-single-crystal and single-crystal-to-amorphous-tosingle-crystal transformation processes between $\left[\mathrm{CdL}_{2}\left(\mathrm{ClO}_{4}\right)_{2}\right] \cdot 11 \mathrm{EtOH} \cdot 6 \mathrm{H}_{2} \mathrm{O}, \quad\left[\mathrm{CdL}_{2}\left(\mathrm{ClO}_{4}\right)_{2}\right] \cdot$ $4 \mathrm{C}_{6} \mathrm{H}_{6} \cdot 3 \mathrm{EtOH} \cdot 4 \mathrm{H}_{2} \mathrm{O}$, and $\left[\mathrm{CdL}_{2}\left(\mathrm{ClO}_{4}\right)_{2}\right] \cdot 6 \mathrm{C}_{6} \mathrm{H}_{6} \cdot \mathrm{H}_{2} \mathrm{O}$. 


\section{DESIGN AND PREPARATION OF ZEOLITE-LIKE FRAMEWORKS}

Many structural motifs have been so far synthesized, in which there is an analogy between the frameworks and natural materials, like minerals, clays, and artificial building architectures, such as pillaredlayer, jungle-gym, etc. Recently, metal-organic microporous coordination networks with zeolitic topology attract considerable attention because of the application in catalytic reactions from not only different metal (element) ions, but also different porous geometry and electronic configurations. For the construction of the zeolite-like topology, four coordinate transition metals and imidazole (or substituted imidazole) type linker have been used [73-76]. The use of the imidazolate as linkers is a deliberate selection since the two coordinating nitrogen atoms are oriented with respect to each other at an angle of $\approx 144^{\circ}$, which is in good agreement with the $\angle \mathrm{Si}-\mathrm{O}-\mathrm{Si}=145^{\circ}$ in zeolite (Fig. 13a). You et al. reported silica-like extended polymorphism in Co-imidazolate, $\left[\mathrm{Co}(\mathrm{im})_{2} \cdot x \mathrm{G}\right]_{n}$, where $x=0.4$ or $0.5, \mathrm{G}=$ guest, and $\mathrm{im}=$ imidazolate. $\left[\mathrm{Co}(\mathrm{im})_{2} \cdot 0.5 \mathrm{py}\right]_{n}$ is a $3 \mathrm{D}$ neutral framework in which $\mathrm{Co}(\mathrm{II})$ are tetrahedrally coordinated and bridged by imidazolate ligand where 1D channels are filled with py molecules (Fig. 13b and 13c) [74]. Recently, Yaghi et al. reported 12 zeolitic imidazolate frameworks (ZIFs) constructed from $\mathrm{Zn}(\mathrm{II})$ or $\mathrm{Co}$ (II) with imidazolate-type linkers and correlated the synthesized 3D networks to the different zeolite networks [75]. They focused on a general strategy to build the structure based on zeolite net and showed that ZIFs have exceptional chemical stability and permanent porosity. Our group also recently extended this idea to make open framework with zeolite-like topology with imidazole dicarboxlylate as a linker and lanthanide ions as a node [76]. We reported two novel isomorphous porous
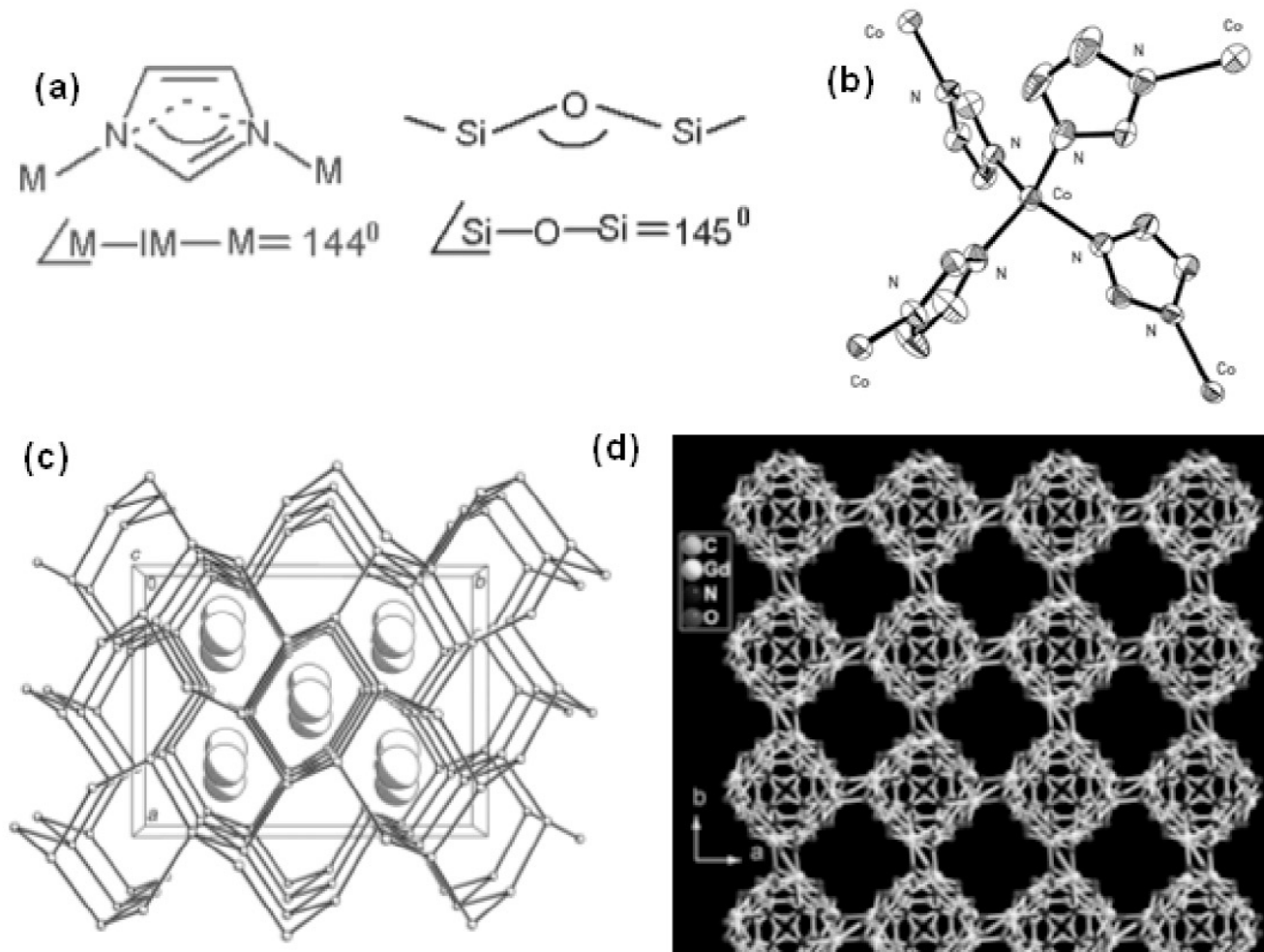

(d)

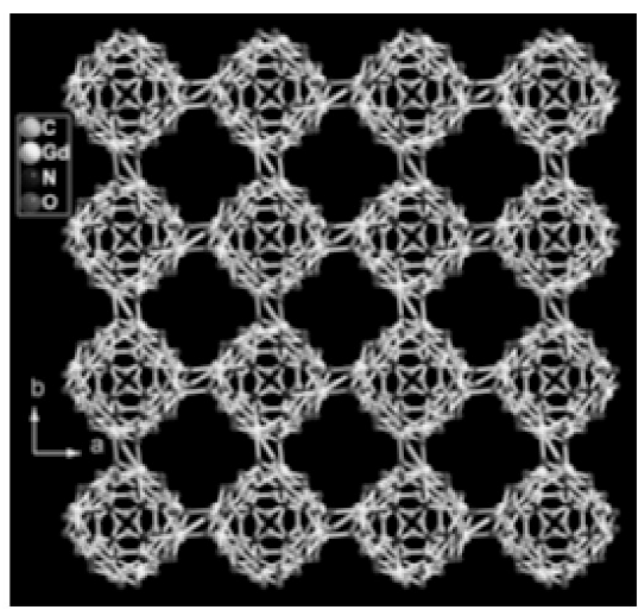

Fig. 13 (a) Schematic diagram of the bridging angles in metal-imidazolates and zeolites; (b) Co(II) coordination environment in $\left[\mathrm{Co}(\mathrm{im})_{2} \cdot 0.5 \mathrm{py}\right]_{n}$; (c) View of the zeolite-like topological diagram of $\left[\mathrm{Co}(\mathrm{im})_{2} \cdot 0.5 \mathrm{py}\right]_{n}$ with $1 \mathrm{D}$ pyridine filled channel; (d) View of the $3 \mathrm{D}$ open zeolite-like network of topology of $\left\{\left[\mathrm{Gd}_{2}\left(\mathrm{imidc}_{2}\left(\mathrm{H}_{2} \mathrm{O}\right)_{3}\right]\left(\mathrm{H}_{2} \mathrm{O}\right)\right\}_{n}\right.$ in crystallographic $a b$ plane. 
frameworks of $\mathrm{Ln}(\mathrm{III}),\left\{\left[\mathrm{Ln}_{2}(\mathrm{imidc})_{2}\left(\mathrm{H}_{2} \mathrm{O}\right)_{3}\right]\left(\mathrm{H}_{2} \mathrm{O}\right)\right\}_{n}$, $[\mathrm{Ln}=\mathrm{Gd}(\mathrm{III})$ and $\mathrm{Er}(\mathrm{III})$; imidc $=4,5$-imidazole dicarboxylate], which shows zeolite-like network topology (Fig. 13d) and after dehydration transformed to another open framework that exhibits selective adsorption properties for $\mathrm{H}_{2} \mathrm{O}$, over $\mathrm{N}_{2}, \mathrm{CO}_{2}$, and $\mathrm{MeOH}$.

\section{OUTLOOK, NEW FUNCTIONS, AND FUTURE PERSPECTIVES}

The most promising applications of MOFs is storage of small molecules such as $\mathrm{H}_{2}, \mathrm{O}_{2}, \mathrm{~N}_{2}, \mathrm{NO}, \mathrm{CO}_{2}$, and $\mathrm{CH}_{4}$, considering not only important energy sources and environmental hazards but also to understand the physicochemical properties of the confined molecules, which differs from the bulk state $[63,77]$. Much interest and attention has been paid to efficient $\mathrm{H}_{2}$ storage metal-organic coordination networks for replacement of current transportation energy sources. The adsorption or storage of a large amount of hydrogen is difficult in the metal-organic porous networks as the polarizability and size of the hydrogen molecules is very small and the interactions with the pore surfaces of the adsorbent are limited. Thus, frameworks with the small pore and with high reactive or affinity sites will be the potential candidates for the large amount of $\mathrm{H}_{2}$ storage.

The resolution of chiral frameworks for enantioselective sorption and asymmetric heterogeneous catalysis remains a challenging and much unexplored area. The use of chiral template molecules or the employment of enantiomerically pure organic linkers are the options for the preparation of the functional chiral frameworks. But truly chiral microporous materials with enantioselective sorption and catalysis are very difficult to synthesize, and transformation of aldehyde to the chiral secondary alcohol by Lin et al. [71] and the enantioselective transesterification by Kim et al. [21] are the most exciting examples reported so far.

Another exciting and undeveloped area is the systematic design and synthesis of the redox-active porous framework, i.e., oxidation and reduction of the overall framework can be done by the guest molecules, without overall decomposition of the network. If a neutral open framework could be oxidized, it would include free counter anions in the channels or pores, and then it might be applied for anion-exchange materials and also will affect the other properties such as magnetism, etc.

The next step is the cooperative properties with functional frameworks and guests, and a challenging target is the design and synthesis of hybrid materials with the strategic coexistence of multiple properties, such as conductivity, spin-cross-over, optical properties, and porous functionality. In order to achieve such functionalities, one of the approaches is to link the 0D clusters or 1D (M-O-M) inorganic chains having high magnetic anisotropy by using the polycarboxylate to 3D robust framework compared to the long rigid linkers, as the magnetism has dependence of exchange coupling on distance. The introduction of the fluorescent guest or optically active molecules in the porous framework and combination with the diversity of pore structure and functionality would offer a versatile route to optical guest sensing.

In the case of flexible porous frameworks, shrinking and expansion of the framework upon desolvation (or guest loss) or guest accommodations have been reported, although it is very limited. Actually, for the recognition of the particular guest or adsorbates, simultaneously coupled "shrink and expansion" processes are much more important than either of these processes occurring in solitary. In this context, it is significant to design a host framework structure using the judicious choice of the linker and connector that can both shrink and expand in response to the presence and absence of a guest molecule.

In the case of flexible framework materials, introducing a functional part, which tunes the regularity of the pore size and overall porous activity, will result in new routes toward framework engineering and fabrication of new materials. This means the design of the host framework in such a way that contains two different channels with the two different guest molecules and exchange of the one guest molecule will result in the deformation or control of the another pore or channel size, which will reflect in the porous functionalities, such as selective adsorption or separation of the guest molecules. This kind 
of bimodal porous function, which coexists in the same material, will be a future aspect in the development of smart materials.

\section{ACKNOWLEDGMENTS}

This work was supported by Grants-in-Aid for Scientific Research in a Priority Area "Chemistry of Coordination Space" (434) and a CREST/JST program from the Ministry of Education, Culture, Sports, Science, and Technology, Government of Japan.

\section{REFERENCES}

1. A. Corma. Chem. Rev. 97, 2373 (1997).

2. M. E. Davis. Nature 427, 813 (2002).

3. N. Setoyama, T. Suzuki, K. Kaneko. Carbon 36, 1459 (1998).

4. J. Miyawaki, T. Kanda, T. Suzuki, T. Okui, Y. Maeda, K. Kaneko. J. Phys. Chem. B 102, 2187 (1998).

5. S. R. Batten, R. Robson. Angew. Chem., Int. Ed. 37, 1460 (1998).

6. S. Kitagawa, R. Kitaura, S.-I. Noro. Angew. Chem., Int. Ed. 43, 2334 (2004).

7. O. M. Yaghi, M. O'Keeffe, N. W. Ockwig, H. K. Chae, M. Eddaoudi, J. Kim. Nature 423, 705 (2003).

8. S. Kitagawa, M. Kondo. Bull. Chem. Soc. Jpn. 71, 1737 (1998).

9. P. J. Hagrman, D. Hagrman, J. Zubieta. Angew. Chem., Int. Ed. 38, 2638 (1999).

10. B. Moulton, M. J. Zaworotko. Chem. Rev. 101, 1629 (2001).

11. C. Janiak. Dalton Trans. 2781 (2003).

12. O. M. Yaghi, H. Li, C. Davis, D. Richardson, T. L. Groy. Acc. Chem. Res. 31, 474 (1998).

13. M. Eddaoudi, D. B. Moler, H. Li, B. Chen, T. M. Reineke, M. O'Keeffe, O. M. Yaghi. Acc. Chem. Res. 34, 319 (2001).

14. S. E. James. Chem. Soc. Rev. 32, 276 (2003).

15. B. Kesanli, W. Lin. Coord. Chem. Rev. 246, 305 (2003).

16. S.-I. Noro, S. Kitagawa, M. Kondo, K. Seki. Angew. Chem., Int. Ed. 39, 2082 (2000).

17. M. Eddaoudi, J. Kim, N. Rosi, D. Vodak, J. Wachter, M. O'Keeffe, O. M. Yaghi. Science 295, 469 (2002).

18. M. E. Kosal, J.-H. Chou, S. R. Wilson, K. S. Suslick. J. Nat. Mater. 1, 118 (2002).

19. S. S.-Y. Chui, S. M.-F. Lo, J. P. H. Charmant, A. G. Orpen, I. D. Willams. Science 283, 1148 (1999).

20. D. Li, K. Kaneko. J. Phys. Chem. B 104, 8940 (2000).

21. J. S. Seo, D. Whang, H. Lee, S. I. Jun, J. Oh, Y. J. Jeon, K. Kim. Nature 404, 982 (2000).

22. H. Chun, D. N. Dybtsev, H. Kim, K. Kim. Chem. Eur. J. 11, 3521 (2005).

23. B. Chen, N. W. Ockwig, A. R. Millward, D. S. Contreras, O. M. Yaghi. Angew. Chem., Int. Ed. 44, 22 (2005).

24. K. Seki. Chem. Commun. 1496 (2001).

25. L. Pan, K. M. Adams, H. E. Hernandez, X. Wang, C. Zheng, Y. Hattori, K. Kaneko. J. Am. Chem. Soc. 125, 3062 (2003).

26. E. Y. Lee, M. P. Suh. Angew. Chem., Int. Ed. 43, 2798 (2004).

27. S. Kitagawa, K. Uemura. J. Chem. Soc. Rev. 34, 109 (2005).

28. D. Bradshaw, J. B. Claridge, E. J. Cussen, T. J. Prior, M. J. Rosseinsky. Acc. Chem. Res. 38, 273 (2005).

29. M. J. Rosseinsky. Microporous Mesoporous Mater. 73, 15 (2004).

30. A. J. Fletcher, K. M. Thomas, M. J. Rosseinsky. J. Solid State Chem. 178, 2436 (2005).

31. K. Uemura, R. Matsuda, S. Kitagawa. J. Solid State Chem. 178, 2429 (2005). 
32. T. K. Maji, K. Uemura, H.-C. Chang, R. Matsuda, S. Kitagawa. Angew. Chem., Int. Ed. 43, 3269 (2004).

33. D. Maspoch, D. Ruiz-Molina, K. Wurst, N. Domingo, M. Cavallini, F. Biscarini, J. Tejada, C. Rovira, A. Veciana. J. Nat. Mater. 2, 90 (2003).

34. K. Uemura, S. Kitagawa, M. Kondo, K. Fukui, R. Kitaura, H.-C. Chang, T. Mizutani. Chem. Eur. J. 8, 3586 (2002).

35. R. Kitaura, K. Fujimoto, S.-I. Noro, M. Kondo, S. Kitagawa. Angew. Chem., Int. Ed. 41, 133 (2002).

36. R. Kitaura, K. Seki, G. Akiyama, S. Kitagawa. Angew. Chem., Int. Ed. 42, 428 (2003).

37. E. J. Cussen, J. B. Claridge, M. J. Rosseinsky, C. J. Kepert. J. Am. Chem. Soc. 124, 9574 (2002).

38. K. Biradha, Y. Hongo, M. Fujita. Angew. Chem., Int. Ed. 41, 3395 (2002).

39. K. Biradha, M. Fujita. Angew. Chem., Int. Ed. 41, 3392 (2002).

40. K. Takaoka, M. Kawano, M. Tominga, M. Fujita. Angew. Chem., Int. Ed. 44, 2151 (2005).

41. M. P. Suh, J. W. Ko, H. J. Choi. J. Am. Chem. Soc. 124, 10976 (2002).

42. K. Seki. Phys. Chem. Chem. Phys. 4, 1968 (2002).

43. S. Takamizawa, E.-I. Nakata, H. Yokoyama, K. Mochizuki, W. Mori. Angew. Chem., Int. Ed. 42 , 4331 (2003).

44. C. Serre, F. Millange, C. Thouvenot, M. Nogues, G. Marsolier, D. Louer, G. Ferey. J. Am. Chem. Soc. 124, 13519 (2002).

45. S. K. Makinen, N. J. Melcer, M. Parvez, G. K. H. Shimuzu. Chem.-Eur. J. 7, 5176 (2001).

46. M. Edgar, R. Mitchell, A. M. Z. Slawin, P. Lightfoot, P. A. Wright. Chem.-Eur. J. 7, 5168 (2001).

47. G. Alberti, E. Brunet, C. Dionigi, O. Juanes, M. J. d. 1. Mata, J. C. Rodriguez-Ubis, R. Vivani. Angew. Chem., Int. Ed. 38, 3351 (1999).

48. H. J. Choi, M. P. Suh. J. Am. Chem. Soc. 126, 15844 (2004).

49. E. Y. Lee, S. Y. Jang, M. P. Suh. J. Am. Chem. Soc. 127, 6374 (2005).

50. L. C. Tabares, J. A. R. Navarro, J. M. Salas. J. Am. Chem. Soc. 123, 383 (2001).

51. K. Uemura, S. Kitagawa, K. Fukui, K. Saito. J. Am. Chem. Soc. 126, 3817 (2004).

52. R. Matsuda, R. Kitaura, S. Kitagawa, Y. Kubota, T. C. Kobayashi, S. Horike, M. Takata. J. Am. Chem. Soc. 126, 14063 (2004).

53. D. N. Dybtsev, H. Chun, K. Kim. Angew. Chem., Int. Ed. 43, 5033 (2004).

54. D. Li, K. Kaneko. Chem. Phys. Lett. 335, 50 (2001).

55. S.-I. Noro, R. Kitaura, M. Kondo, S. Kitagawa, T. Ishii, H. Matsuzka, M. Yamashita. J. Am. Chem. Soc. 124, 2568 (2002).

56. L. Pan, H. Liu, X. Lei, X. Huang, D. H. Olson, N. J. Turro, J. Li. Angew. Chem., Int. Ed. 42, 542 (2003).

57. G. J. Halder, C. J. Kepert, B. Moubaraki, K. S. Murray, J. D. Cashion. Science 298, 1762 (2002).

58. T. K. Maji, G. Mostafa, R. Matsuda, S. Kitagawa. J. Am. Chem. Soc. 127, 17152 (2005).

59. A. J. Fletcher, E. J. Cussen, T. J. Prior, M. J. Rosseinsky, C. J. Kepert, K. M. Thomas. J. Am. Chem. Soc. 123, 10001 (2001).

60. A. M. Davis, S. J. Teague. Angew. Chem., Int. Ed. 38, 736 (1999).

61. M. Kondo, T. Yoshitomi, K. Seki, H. Matsuzaka, S. Kitagawa. Angew. Chem., Int. Ed. 36, 1725 (1997).

62. M. Kondo, T. Okubo, A. Asami, S.-I. Noro, T. Yoshitomi, S. Kitagawa, T. Ishii, H. Matsuzaka, K. Seki. Angew. Chem., Int. Ed. 38, 140 (1999).

63. R. Kitaura, S. Kitagawa, Y. Kubota, T. C. Kobayashi, K. Kindo, Y. Mita, A. Matsuo, M. Kobayashi, H.-C. Chang, T. C. Ozawa, M. Suzuki, M. Sakata, M. Takata. Science 298, 2358 (2002).

64. R. Matsuda, R. Kitaura, S. Kitagawa, Y. Kubota, R. V. Belosludov, T. C. Kobayashi, H. Sakamoto, T. Chiba, M. Takata, Y. Kawazoe, Y. Mita. Nature 436, 238 (2005). 
65. S. Bourrelly, P. L. Llewellyn, C. Serre, F. Millange, T. Loiseau, G. Ferey. J. Am. Chem. Soc. 127, 13519 (2005).

66. O. M. Yaghi, H. Li. J. Am. Chem. Soc. 118, 295 (1996).

67. K. S. Min, M. P. Suh. J. Am. Chem. Soc. 122, 6834 (2000).

68. T. K. Maji, P. S. Mukherjee, G. Mostafa, E. Zangrando, N. Ray Chaudhuri. Chem. Commun. 1368 (2001).

69. B. Rather, M. J. Zaworotko. Chem. Commun. 830 (2003).

70. O. Ohmori, M. Kawano, M. Fujita. J. Am. Chem. Soc. 126, 16292 (2004).

71. C.-D. Wu, A. Hu, L. Zhang, W. Lin. J. Am. Chem. Soc. 127, 8940 (2005).

72. C.-D. Wu, W. Lin. Angew. Chem., Int. Ed. 44, 1958 (2005).

73. Y.-Q. Tian, C.-X. Cai, J. Ji, X.-Z. You, S.-M. Peng, G.-H. Lee. Angew. Chem., Int. Ed. 41, 1384 (2002).

74. Y.-Q. Tian, C.-X. Cai, X.-M. Ren, C.-Y. Duan, Y. Xu, S. Gao, X.-Z. You. Chem.-Eur. J. 9, 5673 (2003).

75. K. S. Park, Z. Ni, A. P. Côté, J. Y. Choi, R. Huang, F. J. Uribe-Romo, H. K. Chae, M. O’Keeffe, O. M. Yaghi. Proc. Natl. Acad. Sci. USA 103, 10186 (2006).

76. T. K. Maji, G. Mostafa, H.-C. Chang, S. Kitagawa. Chem. Commun. 2436 (2005).

77. S. Kitagawa. Nature 441, 584 (2006). 